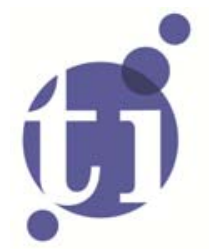

\title{
Does Relative Grading help Male Students? Evidence from a Field Experiment in the Classroom
}

\author{
Eszter Czibor \\ Sander Onderstall \\ Randolph Sloof \\ Mirjam van Praag²
}

${ }^{\prime}$ Faculty of Economics and Business, University of Amsterdam, and Tinbergen Institute, the Netherlands;

2 Copenhagen Business School, Denmark, and Tinbergen Institute, the Netherlands. 
Tinbergen Institute is the graduate school and research institute in economics of Erasmus University Rotterdam, the University of Amsterdam and VU University Amsterdam.

More TI discussion papers can be downloaded at http://www.tinbergen.nl

Tinbergen Institute has two locations:

Tinbergen Institute Amsterdam

Gustav Mahlerplein 117

1082 MS Amsterdam

The Netherlands

Tel.: +31(0)205251600

Tinbergen Institute Rotterdam

Burg. Oudlaan 50

3062 PA Rotterdam

The Netherlands

Tel.: +31(0)10 4088900

Fax: $+31(0) 104089031$

Duisenberg school of finance is a collaboration of the Dutch financial sector and universities, with the ambition to support innovative research and offer top quality academic education in core areas of finance.

DSF research papers can be downloaded at: http://www.dsf.nl/

Duisenberg school of finance

Gustav Mahlerplein 117

1082 MS Amsterdam

The Netherlands

Tel.: +31(0)20 5258579 


\title{
Does Relative Grading Help Male Students? Evidence from a Field Experiment in the Classroom*
}

\author{
Eszter Czibor ${ }^{1}$, Sander Onderstal ${ }^{1,3}$, Randolph Sloof ${ }^{1,3}$ and Mirjam van Praag ${ }^{1,2,3}$ \\ ${ }^{1}$ University of Amsterdam \\ ${ }^{2}$ Copenhagen Business School \\ ${ }^{3}$ Tinbergen Institute
}

August 2014

\begin{abstract}
The provision of non-pecuniary incentives in education is a topic that has received much scholarly attention lately. Our paper contributes to this discussion by investigating the effectiveness of grade incentives in increasing student performance. We perform a direct comparison of the two most commonly used grading practices: the absolute (i.e., criterionreferenced) and the relative (i.e., norm-referenced) grading schemes in a large-scale field experiment at a university. We hypothesize that relative grading, by creating a rank-order tournament in the classroom, provides stronger incentives for male students than absolute grading. In the full sample, we find weak support for our hypothesis. Among the more motivated students we find evidence that men indeed score significantly higher on the test when graded on a curve. Female students, irrespective of their motivation, do not increase their scores under relative grading. Since women slightly outperform men under absolute grading, grading on a curve actually narrows the gender gap in performance.
\end{abstract}

JEL codes: I21, I23, A22, D03, C93

Keywords: education, test performance, grade incentives, competition, gender, field experiment

\footnotetext{
*Acknowledgments. We are grateful to Examination Board of the Faculty of Economics and Business at the University of Amsterdam for authorizing the field experiment, and the Research Priority Area Behavioral Economics of the University of Amsterdam for the generous financial support they provided. We would like to thank Alexander Cappelen, Uri Gneezy, John List, Hessel Oosterbeek, Erik Plug, Andrew Schotter, Bertil Tungodden and Lise Vesterlund for their invaluable advice and inspiration, Sanne Blauw, Thomas Buser, Adam Eric Greenberg, Laura Rosendahl Huber and Dana Sisak for their helpful comments and insights, and Inge Beks for excellent research assistance.
} 


\section{Introduction}

Over the last decades, boys have started to lag behind girls at all levels of education in the developed world. A recent OECD report states: "Compared to girls, boys have become more likely to underperform in secondary education and less likely to complete higher education degrees" (Salvi del Pero \& Bytchkova, 2013, p. 7). ${ }^{1}$ Some governments, worrying about the poor outcomes of boys, have considered specific policies aimed at improving male educational performance (The Economist, 1999). The increasing gender gap has also triggered the attention of popular academic book authors sometimes referred to as belonging to the "boys' movement," producing best-selling titles like 'Boys Adrift' (Sax, 2007) and 'The End of Men' (Rosin, 2012). A variety of reasons have been put forward to explain the educational underachievement of young men, ranging from biological differences in learning styles between the sexes to allegedly "feminine" educational practices favoring girls. From an economist's point of view it is natural to consider another potential explanation: it is possible that grade incentives offered by the educational system do not provide sufficient motivation for boys to do well.

The majority of grading practices that are in use worldwide can be classified into two schemes: absolute and relative grading. Under absolute grading, grades depend solely on students' own individual test outcomes, independent of the performance of their classmates on the same test. This scheme is also known as "criterion-referenced grading," because the student's score is compared to an objective criterion. Under relative grading, students' grades depend on their positions in the score distribution of the class. The scheme is also known as "grading on a curve," referring to the bell-shaped curve of the normal distribution. In the United States, colleges typically implement relative grading: ${ }^{2}$ while in continental Europe the absolute scheme prevails (Karran, 2004).

A key difference between the two grading schemes is that relative grading induces direct competition between peers. In the lingo of organizational economics, absolute grading is analogous to a piece rate compensation scheme, while relative grading creates a rank-order tournament in the classroom. Such rank-order tournaments are advocated by theorists as optimal labor contracts inducing efficient effort provision (Lazear \& Rosen, 1981). Evidence from laboratory experiments, however, shows a heterogeneous response to competition: typically, tournament incentives increase the output of male subjects, but does not affect female performance in a mixed-sex environment (Gneezy et al. , 2003).

Based on the empirical stylized fact of gender differences in response to tournaments we hypothesize that grading on a curve, by offering competitive incentives, provides more motivation and leads to higher performance for male students than absolute grading. We expect no such difference for female students. This paper provides a test for the above hypothesis by means of

\footnotetext{
${ }^{1}$ Observing time trends, the 2013 Education at a Glance report notes a particularly strong growth in tertiary graduation rates for women in several OECD countries between 2005 and 2011, while the increase is much smaller for men (OECD, 2013). Moreover, Guiso et al. (2008) find that in more gender-equal cultures, there is no gender gap in math performance among 15-year-olds, while girls largely outperform boys in reading.

${ }^{2}$ As an example, consider the 2005 overview of law school grading curves by Andy Mroch for the Association of American Law Schools: http://www.aals.org/deansmemos/Attachment05-14.pdf
} 
a field experiment. We empirically compare absolute versus relative grading in the naturalistic setting of a Bachelor course with a large number of participants at the University of Amsterdam. Students in our experiment are randomly divided into two treatment groups. All students have to take the same midterm exam, but the grading of this exam differs by treatment: in one group the midterm test is graded on a curve, in the other group on an absolute scale. (The grading schemes are reversed for the end-of-term exam.) Based on various measures capturing effort provision in preparation for and performance in the midterm exam, we provide a direct empirical comparison of the two grading schemes.

For the full sample of participating students we obtain weak support for the hypothesis that relative grading induces higher male performance while not affecting the achievement of female students. As expected, women slightly outperform men under the absolute scheme while the gender gap shrinks under the relative scheme. However, these differences are small in size and are only statistically significant when correcting for demographic, ability, and preference variables. We further observe that the two grading schemes do not differ considerably in terms of the study effort and exam preparation time they induce.

Obviously, in order for students to be responsive to the (differences in) grade incentives, they should be interested in the level of their grades in the first place. If students are mainly interested in passing the course with minimal effort provision and do not attach importance to their grade per se, the incentive effect of grading on a curve is likely to be limited. In policy reports and the popular press, Dutch pupils and students are often accused of having a 'just pass' attitude ( "zesjescultuur"). ${ }^{3}$ Indeed, international comparisons of primary school pupils reveal that although almost all Dutch pupils fulfill the minimum requirements, only few excel and meet truly advanced benchmarks (Jaspers, 2012). The phenomenon is not constrained to primary schools: Dutch university students are found to provide insufficient study effort (Leuven et al. , 2010), leading to high fail rates and long study durations. ${ }^{4}$ Thus, the response of students in our sample to the grade incentives may thus very well be limited to the group of students that attaches importance to grades. To take this potential heterogeneity into account, we also test our hypothesis among the more responsive subsample of students following the English-language ("international") program. We provide evidence of this subgroup being more motivated and high-achieving. We find that international male students score significantly higher when graded on a curve. Female students, whether in the Dutch or the international program, do not respond to relative grading.

To our knowledge, this paper is the first to provide an experimental comparison of absolute grading and grading on a curve in a naturalistic, high-stakes environment ${ }^{5}$ Our field experiment

\footnotetext{
${ }^{3}$ A recent newspaper article (in Dutch) covering the 2012/13 edition of 'The state of education' ('De staat van het onderwijs') report claims already in its title that Dutch pupils are undermotivated. The lead researcher of the report is quoted to say that pupils are satisfied with getting a 6 , i.e. the lowest passing grade: http://www.nrc.nl/nieuws/2014/04/16/rapport-nederlandse-leerlingen-zijn-niet-gemotiveerd/.

${ }^{4}$ From the cohort of students who entered higher education in 2007, less than a third received their Bachelor degree after four years, the nominal duration of the program. Five years after the start, the share of those who successfully graduated was still less than half (Inspectie van het Onderwijs, 2014).

${ }^{5} \mathrm{~A}$ few papers, discussed in detailed in the Literature section, analyze field experiments with competitive grading in the form of comparison to a randomly chosen opponent or rewarding only the top performers. We believe using an actual grading curve makes our setting more realistic and reproduces better the incentives of rank-order tournaments observed in classrooms in practice.
} 
includes a large sample of university students for whom we collect a rich set of control variables (including preferences as well as course-specific and general ability). We also observe different measures for the preparation behavior of students, so we can test whether grade incentives affect how much students study for the exam.

The remainder of this paper is organized as follows. In section 2 , we shortly review the related literature. Section 3 contains the details of our experimental design. In section 4, we provide an overview of our data and some summary statistics. Section 5 presents our results. Section 6 contains a further discussion of the results. We conclude in section 7 .

\section{Literature}

The advantageous and disadvantageous incentive effects of competitive reward schemes have been studied extensively. Early theoretical contributions by Lazear \& Rosen (1981) and Green \& Stokey (1983) develop the argument that tournament-style incentives may outperform piece rates because under relative performance evaluation "common shocks" are filtered out (see also Holmstrom (1982)). Effort incentives can thus be provided with lower risk exposure (i.e. more cheaply). Empirical studies on the incentive effect of competition typically find evidence in line with tournament theory, although the variance in effort levels is much higher than under piece rate incentives (cf. Bull et al. (1987); van Dijk et al. (2001); Harbring \& Irlenbusch (2003)). Müller \& Schotter (2010) provide an experimental test of the predictions of Moldovanu \& Sela (2001) who derive optimal allocations of prizes with risk-neutral agents of heterogeneous ability. Their empirical results show that low-ability workers "drop out" of the tournament by exerting little or no effort whereas high-ability workers put in more effort than predicted by the model.

Response to tournament incentives is found to be heterogeneous not only with respect to ability but also to gender. The gender gap in competitiveness was first documented by Gneezy et al. (2003) who found that male participants solve significantly more mazes under a competitive reward scheme than under piece rate, while no such increase is observed for female subjects in a mixed-sex environment. Their result has been replicated using both laboratory (e.g. Gunther et al. (2010)) and field experiments (e.g., Gneezy \& Rustichini (2004)) as well as naturally occurring data (e.g., Price (2008)). Niederle \& Vesterlund (2011) and Croson \& Gneezy (2009) provide detailed reviews of studies on gender and competition.

A number of theoretical studies compare relative and absolute grading. Becker \& Rosen (1992) and Landeras (2009) bring the tournament model to the classroom and show that with an appropriate reward scheme, grading on a curve can induce a higher performance than absolute grading in the presence of "systemic" noise or correlated individual error terms. Dubey \& Geanakoplos (2010) also compare the two grading schemes and find that absolute grading provides better incentives for students to work, provided student outcomes are independent. Paredes (2012) predicts that the response to grading systems differs by ability: in her model, where students only care about passing the exam, low-ability students exert less and high-ability students exert more effort under absolute than under relative grading. She finds empirical support for these predictions by analyzing quasi-experimental data from a Chilean university where 
they switched from absolute to relative grading in some first-year courses. Comparing student outcomes before and after the change, her identification strategy relies on an (untestable) common trends assumption.

A number of recent empirical studies also focus on the effect of competition in education and obtain gender differences in line with our results. Jurajda \& Münich (2011) find that male and female students of the same ability were equally likely to be admitted to universities in the case of little competition, but men were significantly more likely to be accepted when competition was high. Örs et al. (2013) observe that females outperformed men in a "noncompetitive" national exam while in the same cohort men outperformed women at the very competitive HEC admission exam later on. Morin (forthcoming) studies the effect of intensified competition resulting from a legislative change that created a "double cohort" in Ontario and observes that men's relative performance increases in response. Bigoni et al. (2011) find that competition induces higher effort among male but not among female students in the case of relatively lowstakes homework assignments. Jalava et al. (2014) examine various non-financial incentive schemes for primary school children in low-stakes tests and conclude that boys only increase performance when faced with relative grading. In contrast, De Paola et al. (2013) do not find gender differences in terms of entry into a tournament or performance under competition in a setting where university students self-selected into a competitive scheme in a midterm exam to obtain bonus points. Azmat \& Iriberri (2010) analyze the effect of providing relative performance information to students in a setting where grades are still solely dependent on absolute performance, and find that the feedback has a strong and positive impact on the performance of both girls and boys.

Our paper contributes to the empirical literature on competitive grade incentives by experimentally comparing absolute and relative grading using a design with several advantages. Uniquely, relative grading in our setting involves an actual grading curve where a student's exam grade is determined by his or her place in the class score distribution, mimicking real-life grading practices. The experiment is conducted in a naturalistic setting among students attending a university course ("in the classroom"). The number of participants is high, and students are randomly assigned to treatments (no self-selection). Exams are high-stakes and there is no subjectivity in their evaluation. Administrative data on student characteristics are available, as well as measures of preferences from an incentivized survey. The study effort of students is also observed, allowing us to test whether any change in exam performance is attributable to differences in preparation under the two schemes. 


\section{Context and design}

\subsection{Context}

We conducted a framed field experiment (Harrison \& List, 2004) among students of the University of Amsterdam (UvA), authorized by the Examination Board of the Faculty of Economics and Business at the University of Amsterdam. The experiment took place in the $2^{\text {nd }}$ year BSc course Economics of Markets and Organizations (EMO) during the first block of the 2013/2014 academic year. ${ }^{6}$ The course covered topics from Organizational Economics and Industrial Organizations in a simple game-theoretic framework, based on lectures notes now published as "Economics of Organizations and Markets" (Onderstal, 2014). Over 500 students enrolled in the course and thus participated in our experiment. The large sample size is desirable not only because it allows us to detect potentially small effect sizes but also because it made it nearly impossible for students in the relative grading group to collude against the experimenters by collectively providing low effort. ${ }^{7}$ The attrition rate was relatively low since the class was compulsory for the majority of the enrolled students. The course grade was the unweighted average of grades from a midterm and an end-of-term exam. The two exams covered roughly the same amount of study material and were designed to be of comparable difficulty. In the exams, students had 90 minutes to answer 30 multiple-choice questions (calculations, theory, and literature-related). Both exams were corrected by machines, thus grading was by construction unbiased. In addition, students could earn a bonus point on top of their exam grade by handing in homework assignments in teams of three or four people. During study weeks, students could participate in a lecture (focusing mostly on theory) and a tutorial (discussing exercises, homework solutions and mock exam questions). Class attendance was voluntary.

The course was offered with identical content in both Dutch and English, the latter for students following the English-language Bachelor program (in the following referred to as the "international program"). The majority of students in the international program are foreigners (typically from Central-Eastern Europe, China, and Germany), but the program is also open to aspiring Dutch students. While there are no entry requirements for attending the Dutch program (all applicants who complete the pre-university track in secondary education and pass the standardized national school-leaving exam are admitted to the study), students have to qualify for the international program by taking an English proficiency test and a mathematics entrance test. About one in four applicants is admitted to the English-language Bachelor program. Participants in the two programs thus differ in their ability and arguably also in their level of motivation. For foreign students in the international program, tuition fees and living expenses in Amsterdam often represent a comparatively much larger investment in education than for their Dutch peers, likely increasing the importance they attach to performing well in their studies. Dutch students choosing to comply with the selective entry criteria for the

\footnotetext{
${ }^{6}$ At the UvA, the academic year is divided into six blocks. The first block runs over eight weeks in September and October.

${ }^{7}$ Budryk (2013) reports a case where students successfully boycotted curved grading, using various social media tools to arrange the collusion.
} 
international program and to follow courses in English instead of their mother tongue also signal dedication and higher levels of aspiration. Students in the Dutch program, on the other hand, are not sufficiently motivated (Leuven et al. ,2010). Their attitude can be described by the "zesjescultuur," discussed in the Introduction: instead of striving for excellence, the majority of them merely aim to pass their courses with minimal effort provision. We provide further evidence of this phenomenon in section 5.2.2.

\subsection{Design of the experiment}

This section contains the details of the experimental design. Participants were randomly assigned to one of the two treatment conditions (communicated to students as the "yellow group" and the "blue group" in order to maintain a neutral framing). All students, regardless of this assignment, sat the same midterm and end-of-term exams at the same time and in the same venue. As mentioned earlier, both exams counted with equal weight towards the final course grade and thus represented high stakes for the students. The difference between the groups lay in the grading schemes used in translating exam scores into exam grades: students in one group were graded under a relative scheme in the midterm and an absolute scheme in the end-of-term exam while the schemes were reversed in the other group, as shown in Table 1. This design allows for a clean comparison of the effect of the two grading schemes on midterm exam performance while maintaining an ex ante fair and equal treatment of students in the two groups. $^{8}$

We performed a stratified randomization along the dimensions we suspected would influence the response to the grading schemes, i.e., gender, study program, and mathematics ability (this information, together with other demographic variables, was available to us prior to the start of the classes). The course has been taught for several years with only small changes in the content, thus the grade distributions of previous years could be taken into account when constructing the curve for relative grading.

The timeline of the experiment is shown in Table 2. Students were informed of their treatment group assignment by e-mail and also by posts on the course intranet page containing all study materials and course-related information. Detailed instructions regarding the grading schemes were included in the Course Manual (see Appendix A) and were also announced during the lectures and tutorials. During the first week, preference and ablity information was collected from students in an online survey (discussed in more detail in section 3.3). For homework assignments, students were required to form teams within their treatment group (in order to reduce potential spillovers), which also increased students awareness of the treatment assignment. Homework results were not published until week 5, so students did not receive any feedback on their relative performance until the midterm exam. Right before the midterm exam, students were required to fill out a short questionnaire testing their understanding of the

\footnotetext{
${ }^{8}$ Our identification relies on the assumption that students only took into account the midterm grading scheme when preparing for and taking the midterm exam, thus their midterm effort choice and performance was unaffected by the grading scheme they were going to face later in the end-of-term test. We revisit this assumption in more detail in section 6 .
} 
grading schemes and collecting information on time spent on the course.

Our main variable of interest is the score (i.e., the number of correct answers) on the midterm exam. Using a between-subject design, we compare the midterm scores of students in the absolute and relative grading groups. Besides the midterm exam scores, in our analysis we also consider the effect of relative grading on a number of proxies for effort provision in preparation for the exam. These proxies are: lecture and tutorial attendance during the study weeks (collected by an assistant and by the tutors), handing in homework assignments, grades of homework assignments, and self-reported study time (collected in the aforementioned questionnaire).

\subsection{Incentivized survey}

We conducted an online survey to collect from students preference, confidence, and ability measures that might influence their response to the two grading schemes (see e.g., Niederle \& Vesterlund (2007) or Gneezy et al. (2003)). We included the survey in the compulsory course requirements, which ensured a very high response rate $(92 \%)$. The survey was incentivized: five respondents were randomly chosen at the end of the course and were paid according to their performance and their choices in the survey (average earning was $€ 215.67$, with a minimum of $€ 100$ and a maximum of $€ 457)$. Respondents spent 21 minutes on average completing the survey which was designed and pre-tested to take about 15-20 minutes, suggesting the majority of students took the task seriously and did not answer at random. The survey was programmed using the software Qualtrics.

The survey was framed as assessing familiarity with the prerequisites for the course, and contained a timed multiple-choice quiz with 10 questions related to first-year mathematics and microeconomics courses (e.g., simple derivations, perfect competition, Nash-equilibria, etc.). ${ }^{9}$ Performance on the quiz serves as an ability measure in our analysis. Before solving the quiz, students were required to choose the reward scheme applied to their quiz performance by reporting their switching point between a constant piece rate and a tournament scheme with an increasing prize. We developed this measure to serve as a proxy for competitive preferences. Moreover, we collected four different measures of overconfidence ${ }^{10}$ (ex ante and ex post; absolute and relative): students were asked to report their expected absolute score and relative rank both before and after solving the quiz,. In addition, risk and ambiguity preferences of participants were measured by eliciting switching points in Holt \& Laury (2002)-style choice menus (see Figure 6 in Appendix B) and also by asking students to rate their willingness to take risk in general (Dohmen et al. , 2011). Finally, students reported their expectations regarding their absolute and relative performance in the course and also their attitudes toward norm- and criterion-referenced grading practices.

\footnotetext{
${ }^{9}$ For an example of a quiz question, please refer to Figure 5 in Appendix B.

${ }^{10}$ We define an agent as overconfident when her conceived ability exceeds her true ability. For a discussion on different definitions of overconfidence in the experimental psychology literature, please refer to Hvide (2002).
} 


\section{Data}

This section contains an overview of our data. Panel A of Table 3 presents basic demographic information based on administrative data provided by the University of Amsterdam. In total, 529 students registered for the course, with a quarter following the international program. The share of female students in the sample is relatively low, just over a third, reflecting the general gender composition of the Economics and Business Bachelor program. The average age is 20.8 with relatively low variance. The majority of the participants were born in the Netherlands and are Dutch citizens. Our dataset contains several indicators of the past academic achievement of the students in our sample, most notably the average mathematics grade and the number of retake exams. The first, constructed as the unweighted average of any mathematics- or statistics-related exam a student had ever taken at the UvA (including failed tests), is a fairly good predictor of the final grade in the EMO course: the correlation between the two is 0.50 and is highly significant. This math-grade based measure indicates very low average performance: the mean of the variable, 5.88, is barely above the minimum requirement for passing. ${ }^{11}$ The second indicator is calculated as the number of retake exams over all the courses the student ever registered for. On average, students repeat approximately one out of five exams. ${ }^{12}$

Panel B of Table 3 provides an overview of the preparation behavior and performance of students in the EMO course. Attendance rates were relatively low during the study weeks preceding the midterm exam: out of the three lectures and tutorials, students participated on average 1.21 and 1.45 times, respectively. The majority of students handed in homework assignments and obtained fairly good homework grades (a mean of 6.95 out of 10), varying in the range between 3.45 and 9.45. (A homework grade of 5.5 or above ensured the bonus point.) Students reported spending on average 10 hours per week on studying and practicing for the course. The show-up rate at both of the exams was very high, $91 \%$ at the midterm and $87 \%$ at the end-of-term exam. The average number of correct answers on the midterm exam was 19.28 out of 30 , which decreased to 17.41 in the end-of-term exam. ${ }^{13}$ Analyzing the final grades, note that it was theoretically possible to get a grade 11 in this course (two students indeed received a calculated grade of 10.5) because the homework bonus point was added to the unweighted average of the two exam grades.

Results from the incentivized online survey are presented in Panel C of Table 3. The relatively low average performance on the quiz measuring knowledge in prerequisites ( 4.67 correct answers out of 10 questions) is likely explained by the intense time pressure students were subjected to during the quiz (25 seconds per question). Performance on the quiz is significantly correlated with the final grade students received in the course $($ corr $=0.23)$. Students are on

\footnotetext{
${ }^{11}$ In the Netherlands, grades range from 1 (lowest) to 10 (highest), and the minimum passing grade is either 5.5 (when half grades are awarded) or 6 .

${ }^{12}$ Note that neither of these ability measures based on past performance are available for the 32 exchange students who visited the UvA only for the semester when our study was conducted.

${ }^{13}$ We argue that this decrease does not reflect a difference in the difficulty of the exams but is rather a result of the way the final grade for the course was determined: a high midterm grade and a homework bonus point would ensure that a student passed the course simply by showing up at end-of-term exam, providing weaker incentives for effort provision in the end-of-term. We further discuss this finding in the Results section.
} 
average overconfident according to all confidence measures we have elicited. In the table we present the ex ante relative overconfidence variable, based on a comparison between the students' guessed and actual relative performance. A correct guessed rank would correspond to a score of zero on our overconfidence scale, and any positive number indicates overconfidence. As mentioned in the previous section, students' risk, ambiguity, and competitive preferences were measured in Holt \& Laury (2002)-style choice lists. We find respondents to be risk-averse (the risk-neutral switching point is at decision 5) but seeking competition (a risk-neutral agent who believes he/she will win half of the time is indifferent between piece rate and tournament at decision 7). The overconfidence of students is also reflected in their grade expectations exceeding their realized final grades (an average of 7.04 vs. 6.65) and their relative performance in terms of grades (students guess on average that out of 100, only 37.37 of their peers will do better than them). Students report a more positive attitude toward absolute than towards relative grading, which is likely due to their inexperience with the latter scheme: students rarely face explicit relative grading in the Dutch educational system. Still, students are not opposed to relative grading: on average they rated their attitude toward grading on a curve as slightly positive ( 5.33 where 5 corresponds to neutral).

Section I of Table 4 proves that the randomization is successful. The two treatment groups are balanced not only along the dimensions we have stratified (study program, gender, and mathematics grades), but also with respect to other demographic, ability, and preference variables. ${ }^{14}$ Section II compares the male and female students in our sample. We observe that women are more likely than men to follow the international program and are thus less likely to have been born in the Netherlands. There is also a gender difference in past academic performance: on average, women obtained significantly higher math grades and had to retake fewer exams than their male peers. ${ }^{15}$ We find no such difference in the number of correct quiz questions, possibly due to the intense time pressure in the survey (Shurchkov, 2012). In terms of preferences, we find that men and women differ in their attitudes toward risk, with women being significantly more risk averse. This finding is in line with results from other studies (Croson \& Gneezy, 2009). ${ }^{16}$ Contrary to our expectations, we find no significant gender differences in the willingness to enter tournaments. This may be explained in part by the women in our sample being as confident as male students. Moreover, the continuous measure we designed (eliciting a switching point between a piece rate and a competitive payment scheme with varying prizes) has not been verified by other studies to reliably capture competitive preferences and could potentially have been confusing for our subjects. ${ }^{17}$ Section III of Table 4 shows the differences

\footnotetext{
${ }^{14}$ Table $\mathrm{C} 1$ in Appendix C provides the same comparison but split by gender. We find that male students in the "Blue" group do not differ from men in the "Yellow" group, except in terms of their ambiguity aversion. Similarly, women in the two treatment groups are not significantly different in their demographic and ability characteristics, although female students in the "Yellow" group report higher expected grades. Once we apply the Bonferroni correction for multiple comparisons, neither of these differences remains significant.

${ }^{15}$ The difference is not driven merely by the higher share of international students among women. Even after controlling for the study program, women obtain significantly higher grades than the men in our sample.

${ }^{16}$ The review and meta-analysis by Filippin \& Crosetto (2014) suggests, however, that the gender differences in risk-taking observed in the literature are sensitive to the methods of elicitation and are often economically insignificant.

${ }^{17}$ Gneezy \& Pietrasz (2013) use a continuous measure to elicit competitive preferences and find large gender
} 
between students following the Dutch and the international program. We find that students in the English-language program outperform their Dutch peers: they have significantly higher mathematics grades, have fewer retakes, and solve more quiz questions correctly. It is therefore understandable that they also have higher grade expectations than students in the Dutch study program. $^{18}$

\section{Results}

\subsection{Selection}

Before comparing the outcomes of students in the two treatment groups, we need to alleviate concerns related to non-random attrition. Students assigned to relative grading who are particularly averse to competition may decide to skip the midterm exam or to drop out of the course entirely, biasing our estimation results. The findings of Niederle \& Vesterlund (2007) and several replications suggest that even high-ability women are likely to shy away from competition. We would thus expect to see lower midterm show-up in the relative grading group, driven by fewer female students participating in the exam. We find no support for this hypothesis in our data: show-up is actually slightly higher under relative grading (a raw difference of 4.9 percentage points, significant at the $5 \%$ level), and there is no gender difference in the propensity to participate in the exam (a t-test yields a p-value of 0.23 ). Selection does not ruin the balancedness of the two treatment groups, and the actual number of non-participants is very low: 16 vs. 30 in the relative and absolute group, respectively. We thus argue that exam participation is likely unrelated to our treatment, so our results are not biased by non-random selection.

\subsection{Exam performance}

\subsubsection{Full sample}

We start our analysis with a simple comparison of midterm scores under the different grading schemes. The mean number of correct answers was 19.20 under absolute and 19.37 under relative grading (with standard deviations of 3.79 and 3.81, respectively) out of 30 questions. According to a two-sample t-test with unequal variances, the difference is insignificant (p-value: 0.62). As Figure 1 shows, the distributions of outcomes in the two treatment groups also look very similar. A Kolmogorov-Smirnov test does not reject the equality of the two distributions (exact p-value: 0.99). We proceed to test whether the response to grade incentives differs by gender. Figure 2 compares the mean number of correct answers on the midterm exam by gender and treatment group. While there is an indication of women slightly outperforming men under the absolute scheme and the gender gap shrinking under the relative scheme due to the higher scores of male students, these differences are negligible in size. An OLS regression (with standard errors clustered on the homework team level) confirms that there is no significant

\footnotetext{
differences, but their method is different from the one applied in this research.

${ }^{18}$ Using the Bonferroni correction to account for multiple testing, the differences between men and women in the number of retakes and between international and Dutch students in quiz performance are no longer significant. All other differences highlighted in the table remain significant at the $10 \%$ level.
} 
difference in midterm scores between the treatment groups, and the gender interaction is also insignificant (see columns 1 and 2 of Table 5).

A raw comparison of scores may, however, be misleading: as we have shown in Table 4, men and women in our sample are different along many dimensions that could possibly influence their response to the grading schemes. We therefore repeat the analysis controlling for demographic, ability, and preference variables ${ }^{19}$ and discover that all else equal, men respond more favorably to relative grading than women. Column 3 in Table 5 shows that the coefficient of the interaction term between relative grading and the male dummy is positive and significant at the $5 \%$ level. ${ }^{20}$ The result is robust to the inclusion of further interaction terms (see Table C2 in Appendix C). Analyzing the subsamples of men and women separately (columns 4 and 5 in Table 5) we find that the point estimate for the effect of relative grading on exam scores is negative for female and positive for male students, ceteris paribus, but these estimates are not statistically significant (p-values: 0.17 and 0.16 for men and women, respectively).

Following Paredes (2012) and Müller \& Schotter (2010), we discuss whether we find a difference with respect to ability in response to the grading schemes. As we have already seen in Table $\mathrm{C} 2$, previous academic history, as proxied by the average mathematics-related exam grades, does not influence student reaction to relative grading: the interaction term relative ${ }^{*}$ Math is insignificant. ${ }^{21}$ Results are similar when we use course-specific knowledge (performance on the prerequisites quiz), grades in the first-year finance course or expected grade in the EMO course to capture ability. For an illustration, see Figure 4

\subsubsection{Responsiveness to grade incentives}

In our analysis so far we have compared whether one type of grade incentive works better than the other. In so doing, we have implicitly assumed that all students are in the first place motivated by grade incentives. Those students, however, who place little or no weight on the actual level of their grades are unlikely to respond strongly to differences in grading schemes. As we have discussed in the Introduction, students in the Netherlands are typically only interested in passing their courses and do not strive to achieve high grades.

Besides the examples discussed in the Introduction, our data also contains evidence of the "zesjescultuur." Due to the specific design of the grading schemes. ${ }^{22}$ students who achieved a grade 7 or higher in the midterm exam and received a homework bonus point (in the following referred to as "safe" students) knew they could pass the course simply by showing up at the end-of-term exam, without actually solving any questions correctly. By focusing on the group

\footnotetext{
${ }^{19}$ The control variables included in the regressions (throughout the paper, unless otherwise indicated) are the following: Demographic controls: international program, age, Dutch-born; Ability controls: average math grade, quiz performance; Preference controls: overconfidence, risk aversion, ambiguity aversion, competition aversion and attitude toward relative grading.

${ }^{20}$ The inclusion of covariates leads to changes in the estimates of the main effect not because of an imperfect randomization but due to a reduction in sample size caused by missing ability and preference variables for some students. The significance of the interaction term is not, however, merely driven by the smaller sample.

${ }^{21}$ We find no significant effect when testing for a non-linear relationship by including either Math squared or four dummies for the four Math quartiles. Calculations available from the authors on request.

${ }^{22}$ The lowest grade awarded under both schemes was a 2, see Appendix A.
} 
of "safe" students, we show that even higher ability students tend to be satisfied with the lowest passing grade. Many of these students, instead of striving for a high final grade, provided low effort in the final exam: while the mean score of "safe" students was 23.36 in the midterm exam, it decreased in the end-of-term test to 19.18. Tellingly, 108 out of the 148 "safe" students solved fewer questions correctly in the end-of-term than in the midterm exam. This drop in performance cannot be explained by differences in exam difficulty, since "non-safe" students (who were not certain of having passed the course prior to the end-of-term) only scored 1 point lower on average on the end-of-term compared to the midterm, and more than half of them actually performed better in the second test (see Figure C1 in Appendix C) ${ }^{23}$

The above evidence illustrates that many students are unwilling to work hard for a higher grade. Since they are not worried about failing the course (less than $2 \%$ of them report an expected grade below 6), it is unlikely that they will be responsive to grade incentives in general. We will continue our analysis to test whether the response to absolute vs. relative grading is heterogeneous with respect to sensitivity to grade incentives. The proxy we use to measure such "responsiveness" is the study program students follow: we argue that those enrolled in the international program place more weight on the grades in the course than those in the Dutch program.

\subsubsection{International program}

In this subsection we test whether we find a differential effect of relative grading among the 126 students following the international program. Students in the international program are significantly more likely to hand in homework assignments, they receive higher homework grades and report spending more time preparing for the course than students in the Dutch-language program (see Table C3 in Appendix C), supporting our claim that they care more about the grade they receive. Moreover, even after controlling for past mathematics grades or performance on the quiz questions, students in the international program have significantly higher grade expectations than those in the Dutch program. We attribute this difference to international students being more ambitious rather than more overconfident, especially because students in the two programs did not differ in their overconfidence measured in the online incentivized survey.

Figure 3 shows that the response to relative grading indeed differs by study program: while the performance of students in the Dutch program is unaffected by the grading schemes, male students in the international program achieve significantly higher scores when graded on the curve. Table 6, presenting estimates from OLS regressions, confirms that our results are robust to the inclusion of control variables: men in the international program respond significantly

\footnotetext{
${ }^{23}$ We find more indication of the 'just pass' attitude by analyzing results from first-year courses. If all students worked hard to get the highest grade possible and thus the only explanation for low grades would be a lack of ability, than we would expect lower and more variable grades in courses that are mathematics-intensive than in those that are not (assuming that in the latter effort provision can compensate for skill differences). We do not, however, find lower average grades in math-heavy courses such as Micro- and Macroeconomics than in less mathematical classes such as Marketing or Organization and Management, and the difference between the standard deviations is also small.
} 
more positively to relative grading than female students, while no such difference is observed in the Dutch program. The effect of relative grading on the exam performance of male international students is estimated to be approximately 1.5 to 2.2 points (out of 30 ) depending on the specification (Table $\mathrm{C} 4$ in the Appendix shows the effect of relative grading in the international program, splitting the sample by gender). This corresponds to roughly one-third to 0.5 standard deviation of the midterm score in the international program.

Since the mean score of women following the international program does not differ between the two schemes, we find that male relative performance is higher under grading on a curve than under absolute grading. While women in this subsample outperform men under the absolute scheme (a difference of 1.8 points, $\mathrm{p}$-value $=0.07$ from a two-sample t-test with unequal variances), there is no significant gender difference under relative grading.

\subsection{Robustness checks}

In this section we test the robustness of our findings. We start by repeating our analysis on a subsample where we exclude students who do not have a clear understanding of the treatments. As mentioned in section 3.2, directly before writing the midterm exam, students were required to answer multiple-choice questions about the color of the group they were assigned to, the grading scheme applied to their midterm test, and the interpretation of the schemes. The propensity to report misunderstanding the grading schemes did not differ by treatment assignment. Individuals in the absolute grading group were, however, less likely to complete the questionnaire. As our first robustness check, we exclude the 65 students who either reported being unsure of the grading schemes or who gave the wrong answers. The first two columns of Table 7 show that our results do not change qualitatively when restricting the sample in this way. The estimates are no longer significant in the international program subsample, probably due to the reduction in sample size.

We also consider whether our findings are sensitive to the regression specifications we use, in particular to the ability measures we include as controls. We reran our estimations replacing our ability measures (average mathematics grades and performance in the quiz) with the average number of retake exams. Using this specification, we no longer find a significant gender effect in the full sample (column 3 of Table 7 ), while the result becomes even stronger in the international program (column 4, Table 7).

\subsection{Preparation}

Since the assignment to the treatment groups was announced at the beginning of the block, students could take into account their midterm grading scheme when choosing the time and effort to invest in studying. In the following, we compare the preparation behavior between the two grading groups. We start with a simple comparison of means without the inclusion of controls. Figure C2 in Appendix C displays the students' self-reported time devoted to studying for the EMO course. It indicates no effect of relative grading on study times for women: the time spent on reading lecture notes, solving exercises, homework assignments or practice exams 
is the same in the two treatment groups. Men, however, report having spent more time on homework when assigned to relative grading (a t-test shows the difference to be significant at the $5 \%$ level). Conversely, the higher effort of men in the relative group did not translate into higher average homework grades on the first two assignments ( $\mathrm{p}$-value $=0.656$ from a t-test with equal variances) while female students did perform slightly but significantly better (the difference is 0.59 on a scale of 1 to 10$)$.

We continue with a regression analysis of the different aspects of preparation behavior. Table 8 shows that the propensity to hand in homework assignments was uninfluenced by the treatment group assignment (results from a probit estimation). Even after the inclusion of a rich set of control variables, we find that attendance behavior and (an aggregate measure of) study time does not significantly differ between students in the absolute and the relative groups. We find evidence of a small difference in homework grades: all else equal, students facing relative grading received on average a 0.67 point higher homework grade (the effect is larger among female students, but in the model including control variables the difference is also significant among men). We can conclude that if anything, relative grading had a small positive impact on the preparation behavior of students in our sample: men report having spent slightly more time on homework and both genders, but especially women prepared higher-quality assignments in anticipation of being graded on the curve. We find the same tendencies when we restrict the analysis to the international program (see Table C5 in Appendix C).

\section{Discussion}

This section is devoted to the discussion of three issues. First, we explore what mechanism could lead to higher exam scores among responsive men under relative than under absolute grading. Second, we consider the effect of the two grading schemes on the gender gap in performance. Third, we discuss the identifying assumption that students do not take into account the endof-term grading scheme when taking the mid-term exam.

In the previous subsection we found no consistent effect of relative grading on behavior before the exam: according to most measures, students in the two treatment groups differed little in how hard they prepared for the course. This result remains true if we limit the analysis to the subsample of international students. This leads us to argue that the increase we observe in the test scores of male international students graded on the curve is not necessarily explained by a better knowledge of the course material. Instead, we speculate that relative grading boosts the effort provision on these students during the exam itself. Even though the treatment was announced weeks ahead, its salience was increased again for the exam: directly before the test, students were asked to complete a questionnaire related to the treatments, focusing their attention on the particular grading scheme that applied to them. We also included details of the relevant grading schemes on the front page of the exam booklets. We can thus be sure that students were aware of the grade incentives when working on the test questions.

This explanation is in line with the results of Jalava et al. (2014) and Levitt et al. (2013) who find that incentives introduced unexpectedly before an exam (that could not possibly affect 
preparation) can have a significant impact on test scores. Similarly, in laboratory experiments we also observe that subjects respond to different incentive schemes by changing their effort provision, influencing their task performance even though their level of skills or knowledge is unaffected (see, for instance, van Dijk et al. (2001)). The fact that we observe a relatively small effect size in our data (motivated men solve correctly 1.5-2.2 exam questions more out of 30 when graded on a curve) is compatible with the above explanation: on a test designed to capture course-specific knowledge, there is limited room to increase scores by working harder during the exam itself.

The second issue we discuss is how the gender gap in performance is affected by relative grading. We have consistently found a gender difference in response to relative grading: men react more positively to grading on a curve than women. Female students, irrespective of being classified as motivated by our proxies, do not significantly differ in their preparation behavior or exam performance under the two grading schemes. Since motivated men do score higher when graded on the curve, relative grading increases male relative performance in these subsamples. This change is most evident in the international program, where women significantly outperform men under the absolute, but not under the relative scheme, as shown in Figure 3. Therefore, higher male relative performance under grading on a curve actually diminishes the gender gap in exam performance.

We also examine the effect of relative grading on the gender balance among the top and bottom performers (see Table C6 in Appendix C). We find that the share of women in the top quartile of midterm scores is higher under absolute than under relative grading $(39.2 \%$ vs. $33.3 \%$ ), but this difference is not significant. Similarly, the share of women in the bottom quartile is slightly and insignificantly lower under absolute than under relative grading $(26.7 \%$ vs. $34.4 \%$ ). Since the share of female students is $34.3 \%$ in the full sample, grading on a curve ensures a more balanced representation of the genders among the best and worst performers. A similar picture emerges if we focus on the subsample of students in the international program.

Finally, we discuss a limitation of our design. As mentioned earlier, the identification of the effect of the grading systems relies on the assumption that students, when preparing for and taking the midterm exam, only focus on the midterm grading scheme they are assigned to and do not consider the end-of-term scheme that awaits them. In particular, we need the tendency of students to substitute effort between the two exams to be uncorrelated with their treatment group assignment. We believe this assumption holds since students were in general unlikely to shift effort from the midterm to the end-of-term exam. As previously discussed, performance on the midterm exam had great importance for the students: with a high enough test grade (and a homework bonus point), students were sure to have already passed the course after the midterm. Students were thus incentivized to take the midterm exam seriously and not substitute effort from the first exam to the second. Admittedly, our identifying assumption is untestable, but the reversal of grading schemes is required to perform the experiment while ensuring ex ante fair treatment of our subjects. 


\section{Conclusions}

This paper reviews evidence from a field experiment comparing the two most commonly used grading practices: the absolute and the relative scheme. Overall we conclude that the incentive effect of relative grading is limited when measured using the full sample of participating students. However, test scores among a subsample of students who are arguably and verifiably motivated by grade incentives show a picture in line with expectations: male students increase their performance when graded on the curve, whereas the performance of female students is unaffected by the grading systems. These findings suggest that absolute grading does not provide sufficiently strong motivation for male students. In particular, the more ambitious men could be given stronger incentives by grading them competitively. This would not harm the absolute performance of female students, as they do not respond to the induced competition. Unfortunately, however, relative grading does not help to incentivize the less-motivated males, the arguably most problematic group. Other incentive instruments may potentially prove helpful here. Monetary incentives to improve student achievement have been studied by Leuven et al. (2010), Fryer (2011) and Braun et al. (2011), while Levitt et al. (2013) and Jalava et al. (2014) look at non-pecuniary incentives such as certificates and trophies. Grove \& Wasserman (2006) study whether making assignments count toward the final grade improves student learning and exam performance.

We should also keep in mind that the increased performance of male students in the international program did not seem to result from better preparation but rather from more concentration or greater effort provision during the exam itself. It is therefore not clear whether competitive incentives led to a better "deep knowledge" of the course material. Furthermore, female students in our sample put slightly more effort into preparation under both grading schemes. Exam scores under absolute grading reflect this gender difference in study effort more accurately.

An important direction for future research is to test whether our findings replicate in different environments. First, students in our sample were accustomed to an absolute grading scheme and for the most part never experienced relative grading during their university studies. It is possible that incentives work differently among students for whom the "default" scheme is competitive grading. Second, women in our study, although underrepresented in the Bachelor program, slightly outperformed men during their previous courses and under absolute grading. Here, grading on a curve actually narrows the gender gap in exam performance. A decrease in female relative performance would be much more alarming in environments where men on average performed better, as discussed by Niederle \& Vesterlund (2010). 


\section{Tables and figures}

\section{Tables}

Table 1: Overview of treatment groups and grading schemes

\begin{tabular}{lcc}
\hline & "BLUE" group & "YELLOW" group \\
& absolute & relative \\
Midterm exam & relative & absolute \\
\hline
\end{tabular}

Table 2: Timeline of the experiment

Week 1 Study week Announce treatment group assignment

Week 2 Study week Deadline for survey; forming homework teams

Week 3 Study week Deadline homework 1

Week 4 Exam week Deadline homework 2; Questionnaire \& Midterm exam

Week 5 Study week Results homework 1-2 published

Week 6 Study week Deadline homework 3

Week 7 Study week Deadline homework 4

Week 8 Exam week Results homework 3-4 published, Final exam 
Table 3: Summary statistics for demographic variables, course and survey outcomes

MEAN STD. DEV. MIN. MAX. N

PANEL A: DEMOGRAPHICS

international program

0.25

0.34

0.44

$\begin{array}{lll}0 & 1 & 529\end{array}$

female

0.48

age

20.84

2.08

$\begin{array}{lll}0 & 1 & 527\end{array}$

Dutch-born

0.74

0.44

$18 \quad 35$

485

Dutch nationality

0.79

0.41

517

avg. math grade

5.88

1.49

0

avg. number of retakes

0.22

0.23

13

$\begin{array}{lll}1.13 & 10 & 463\end{array}$

$0 \quad 1.43$

475

PANEL B: COURSE OUTCOMES

lecture attendance(scale 0 -3)

1.21

0.94

$$
0
$$

3

517

1.45

1.00

$\begin{array}{lll}0 & 3 & 529\end{array}$

handing in $\mathrm{HW}(0 / 1)$

0.81

0.39

$\begin{array}{lll}0 & 1 & 529\end{array}$

average HW grade (scale 0 - 10)

6.95

1.13

self-reported study time (scale 1-5)

2.42

0.77

$\begin{array}{lll}3.45 & 9.45 \quad 427\end{array}$

midterm show-up (0/1)

0.91

end-of-term show-up (0/1)

0.87

0.28

$\begin{array}{lll}1 & 5 & 385\end{array}$

midterm score (scale 0 -30)

end-of-term score (scale 0-30)

19.28

0.34

$\begin{array}{lll}0 & 1 & 529\end{array}$

final grade (scale 1 - 11)

17.41

3.8

$\begin{array}{lll}0 & 1 & 529\end{array}$

4.27

$8 \quad 29$

483

6.65

1.33

$4 \quad 27$

461

$2.5 \quad 10.5 \quad 461$

\title{
PANEL C: SURVEY OUTCOMES
}

survey complete $(0 / 1)$

0.92

4.67

0.28

1.67

$\begin{array}{lll}0 & 1 & 529\end{array}$

quiz questions (scale 0-10)

18.23

29.65

risk aversion (scale 0-10)

6.10

1.91

$\begin{array}{lll}0 & 10 & 486\end{array}$

ambiguity aversion (scale 0-10)

competition aversion (scale 0-10)

7.44

3.14

$\begin{array}{lll}-78 & 100 & 487\end{array}$

expected grade (scale 0-10)

6.42

2.83

$\begin{array}{lll}1 & 11 & 487\end{array}$

expected rank (scale 0-100)

7.04

0.89

$11 \quad 487$

attitude absolute grading (scale 0 -10)

attitude relative grading (scale 0-10)

37.37

17.81

1.82

2.75

11486

8.88

5.33

$10 \quad 485$

$100 \quad 485$

$\begin{array}{ccc}0 & 100 & 485 \\ 1 & 11 & 485\end{array}$

(2)

\begin{abstract}
.
\end{abstract}


Table 4: Comparison of means by treatment group, gender, and study program

SECTION I.

SECTION II.

SECTION III.

BLUE YELLOW Diff. MEN WOMEN Diff. DUTCH INT. Diff.

DEMOGRAPHICS

int. program

$\begin{array}{cccc}0.259 & 0.247 & 0.199 & 0.348 \\ (0.027) & (0.027) & (0.022) & (0.036)\end{array}$

female

$0.341 \quad 0.346$

$(0.029) \quad(0.030)$

age

$20.890 \quad 20.782$

$(0.147) \quad(0.117)$

Dutch born

$0.738 \quad 0.748$

$(0.027) \quad(0.027)$

$\begin{array}{cccccc}- & - & & 0.299 & 0.477 & * * * \\ & & & (0.023) & (0.044) & \\ 20.874 & 20.766 & & 20.880 & 20.677 & \\ (0.113) & (0.170) & & (0.110) & (0.176) & \\ 0.795 & 0.652 & * * * & 0.924 & 0.224 & * * * \\ (0.022) & (0.036) & & (0.014) & (0.036) & \end{array}$

ABILITY

Math grade

$5.890 \quad 5.861$

(0.096) (0.101)

num. retakes

$0.226 \quad 0.220$

(0.014) (0.015)

quiz questions

$4.730 \quad 4.612$

(0.102) (0.112)

$\begin{array}{cc}5.740 & 6.141 \\ (0.084) & 0.122 \\ 0.237 & 0.196 \\ (0.013) & (0.017) \\ 4.738 & 4.517 \\ (0.096) & (0.120)\end{array}$

5.717

6.504

(0.077) (0.148)

$0.240 \quad 0.153$

$(0.012) \quad(0.022)$
4.579

$4.579 \quad 4.936$

(0.087) (0.151)

\section{PREFERENCES}

overconfidence

$16.857 \quad 19.609$

(1.847) (1.952)

risk aversion

$6.111 \quad 6.086$

$17.299 \quad 20.093$

$17.743 \quad 19.640$

(1.700) (2.194)

(1.554) (2.680)

$\begin{array}{cc}6.111 & 6.086 \\ (0.126) & (0.119)\end{array}$

ambig. aversion

$\begin{array}{ll}7.660 & 7.222\end{array}$

5.892

6.465

6.019

6.328

$(0.202) \quad(0.201)$

(0.108)

(0.141)

$(0.099) \quad(0.175)$

$\begin{array}{ll}7.519 & 7.308\end{array}$

$7.409 \quad 7.536$

$6.369 \quad 6.471$

(0.179)

$(0.166)$

$(0.278)$

comp. aversion

(0.184) (0.180)

expected grade

$\begin{array}{cc}6.988 & 7.087 \\ (0.057) & (0.056)\end{array}$

6.364

6.460

6.304

\begin{tabular}{ll}
$(0.153) \quad(0.232)$ \\
\hline
\end{tabular}

$(0.148)$

$(0.261)$

$7.074 \quad 6.959$

6.850

7.576

$(0.051) \quad(0.065)$

$(0.043) \quad(0.079)$

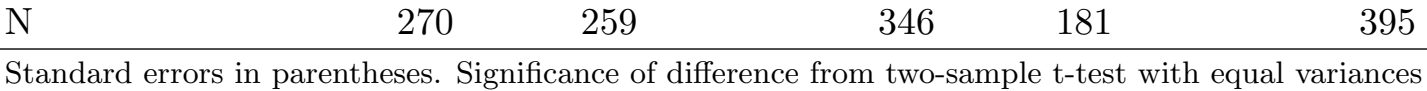

${ }^{*} p<0.10,{ }^{* *} p<0.05,{ }^{* * *} p<0.01$ 
Table 5: Estimates of the effect of relative grading on midterm scores

FULL SAMPLE

SUBSAMPLES

No controls Gender interaction With controls Men Women

\begin{tabular}{lccccc}
\hline & & & & & \\
relative & 0.170 & -0.064 & -0.646 & 0.563 & -0.721 \\
& $(0.376)$ & $(0.607)$ & $(0.482)$ & $(0.400)$ & $(0.518)$ \\
relative*male & & 0.300 & $1.223^{* *}$ & & \\
& & $(0.729)$ & $(0.594)$ & & \\
male & & -0.431 & $-0.864^{*}$ & & \\
& & $(0.504)$ & $(0.448)$ & & \\
Demographic controls & - & - & $\checkmark$ & $\checkmark$ & $\checkmark$ \\
Ability controls & - & - & $\checkmark$ & $\checkmark$ & $\checkmark$ \\
Preference controls & - & - & $\checkmark$ & $\checkmark$ & $\checkmark$ \\
$N$ & 483 & 0.002 & 0.275 & 0.280 & 0.342 \\
$R^{2}$ & 0.000 & & & & \\
& & & &
\end{tabular}

Results from OLS regressions; dependent variable: midterm score.

Standard errors, clustered on the homework team level, in parentheses; ${ }^{*} p<0.10,{ }^{* *} p<0.05,{ }^{* * *} p<0.01$

Table 6: Estimates of the effect of relative grading on midterm scores: international vs. Dutch program

INTERNATIONAL

No controls With controls No controls With controls

\begin{tabular}{|c|c|c|c|c|}
\hline relative & $\begin{array}{l}-0.333 \\
(1.072)\end{array}$ & $\begin{array}{c}-1.101 \\
(0.770)\end{array}$ & $\begin{array}{c}0.015 \\
(0.706)\end{array}$ & $\begin{array}{l}-0.389 \\
(0.583)\end{array}$ \\
\hline relative*male & $\begin{array}{c}2.576^{*} \\
(1.480)\end{array}$ & $\begin{array}{l}2.578^{* *} \\
(1.101)\end{array}$ & $\begin{array}{c}-0.259 \\
(0.776)\end{array}$ & $\begin{array}{c}0.657 \\
(0.667)\end{array}$ \\
\hline male & $\begin{array}{l}-1.830^{*} \\
(0.932)\end{array}$ & $\begin{array}{c}-2.101^{* *} \\
(0.780)\end{array}$ & $\begin{array}{c}0.233 \\
(0.583)\end{array}$ & $\begin{array}{l}-0.377 \\
(0.504)\end{array}$ \\
\hline Demographic controls & - & $\checkmark$ & - & $\checkmark$ \\
\hline Ability controls & - & $\checkmark$ & - & $\checkmark$ \\
\hline Preference controls & - & $\checkmark$ & - & $\checkmark$ \\
\hline$N$ & 126 & 90 & 356 & 329 \\
\hline$R^{2}$ & 0.053 & 0.500 & 0.001 & 0.206 \\
\hline
\end{tabular}


Table 7: Robustness checks

AWARE OF GRADING SCHEME DIFFERENT ABILITY CONTROL

Full sample International Full sample International

\begin{tabular}{lcccc}
\hline & & & & \\
relative & -0.606 & -0.806 & -0.511 & -1.178 \\
& $(0.477)$ & $(0.830)$ & $(0.577)$ & $(1.088)$ \\
relative*male & $1.230^{* *}$ & 1.714 & 0.965 & $3.453^{* *}$ \\
& $(0.619)$ & $(1.201)$ & $(0.720)$ & $(1.296)$ \\
male & $-0.887^{* *}$ & -1.209 & $-0.783^{*}$ & $-2.127^{*}$ \\
& $(0.446)$ & $(0.938)$ & $(0.469)$ & $(1.063)$ \\
Demographic controls & $\checkmark$ & $\checkmark$ & $\checkmark$ & $\checkmark$ \\
Ability controls $\dagger$ & $\checkmark$ & $\checkmark$ & - & $\checkmark$ \\
Number of retakes & - & - & $\checkmark$ & $\checkmark$ \\
Preference controls & $\checkmark$ & $\checkmark$ & $\checkmark$ & 90 \\
$N$ & 365 & 79 & 426 & 0.296 \\
$R^{2}$ & 0.275 & 0.406 & 0.160 & \\
\end{tabular}

Results from OLS regressions; dependent variable: midterm score.

Standard errors, clustered on the homework team level, in parentheses; ${ }^{*} p<0.10,{ }^{* *} p<0.05,{ }^{* * *} p<0.01$

$\dagger$ : average Mathematics grades and performance in the quiz

Table 8: Estimates of the effect of relative grading on preparation behavior

\begin{tabular}{|c|c|c|c|c|}
\hline & $\begin{array}{c}(1) \\
\text { handing in HW }\end{array}$ & $\begin{array}{c}(2) \\
\text { avg. HW }\end{array}$ & $\begin{array}{c}(3) \\
\text { attendance }\end{array}$ & $\begin{array}{c}(4) \\
\text { study time }\end{array}$ \\
\hline relative & $\begin{array}{c}0.345 \\
(0.257)\end{array}$ & $\begin{array}{l}0.665^{* *} \\
(0.307)\end{array}$ & $\begin{array}{c}0.011 \\
(0.248)\end{array}$ & $\begin{array}{l}-0.054 \\
(0.129)\end{array}$ \\
\hline relative*male & $\begin{array}{l}-0.096 \\
(0.300)\end{array}$ & $\begin{array}{l}-0.252 \\
(0.326)\end{array}$ & $\begin{array}{c}0.033 \\
(0.275)\end{array}$ & $\begin{array}{c}0.072 \\
(0.166)\end{array}$ \\
\hline male & $\begin{array}{l}-0.301 \\
(0.195)\end{array}$ & $\begin{array}{c}0.124 \\
(0.275)\end{array}$ & $\begin{array}{l}-0.014 \\
(0.212)\end{array}$ & $\begin{array}{l}-0.239^{*} \\
(0.126)\end{array}$ \\
\hline Demographic controls & limited & $\checkmark$ & $\checkmark$ & $\checkmark$ \\
\hline Ability controls & - & $\checkmark$ & $\checkmark$ & $\checkmark$ \\
\hline Preference controls & - & $\checkmark$ & $\checkmark$ & $\checkmark$ \\
\hline Tutor controls & - & $\checkmark$ & - & - \\
\hline$N$ & 527 & 363 & 429 & 334 \\
\hline$($ pseudo- $) R^{2}$ & 0.078 & 0.206 & 0.026 & 0.109 \\
\hline
\end{tabular}




\section{Figures}

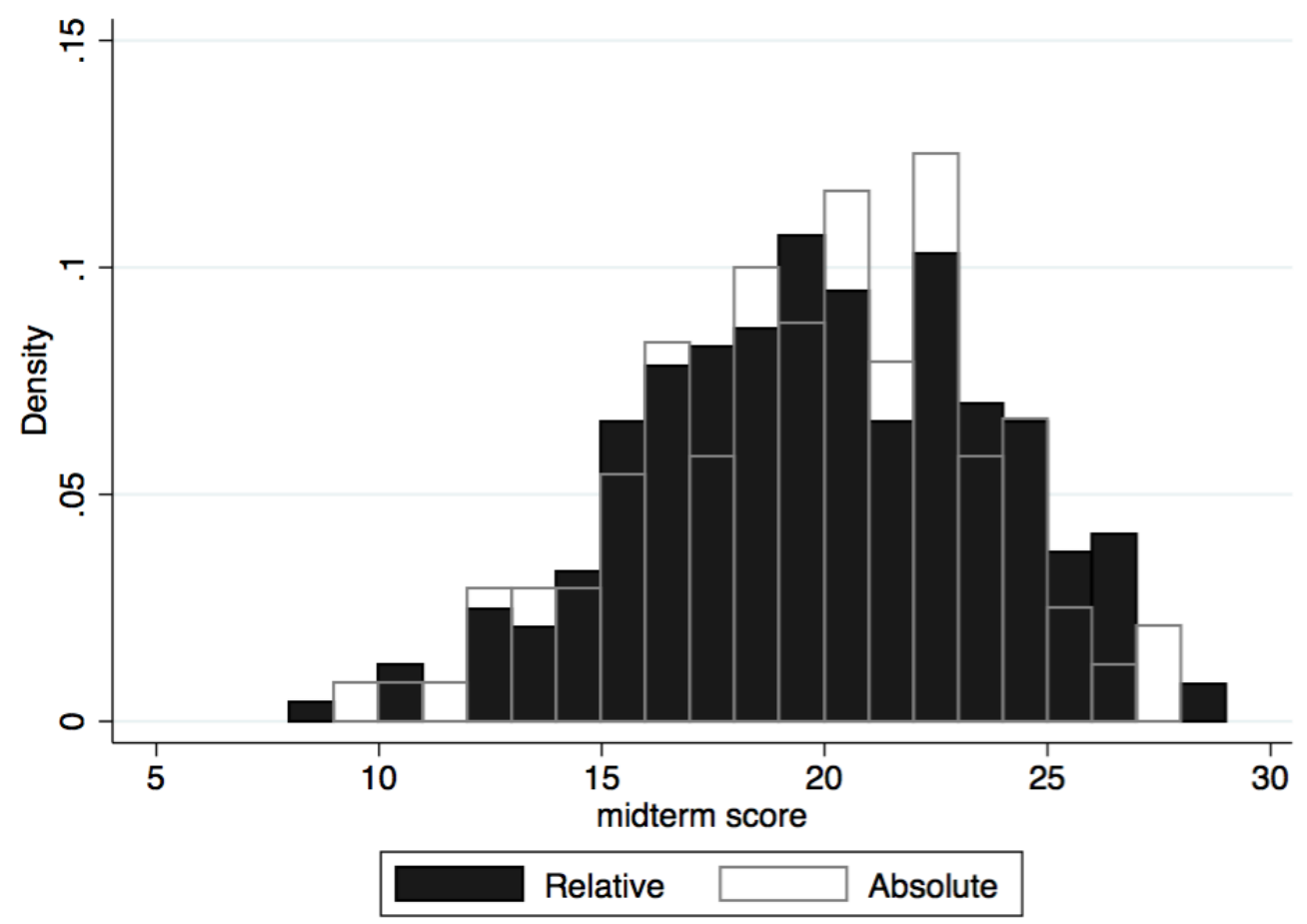

Figure 1: Distribution of midterm exam scores by treatment group

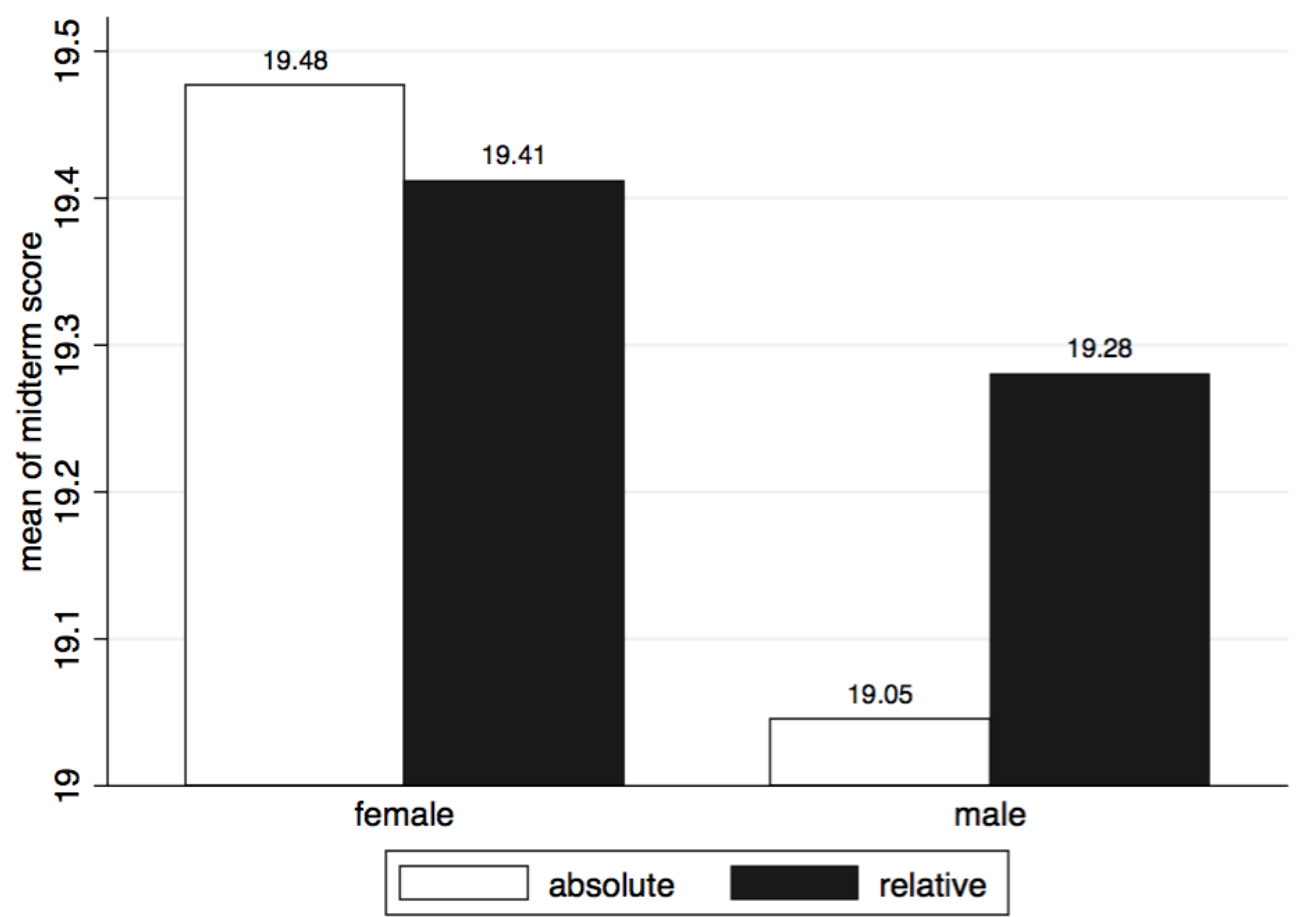

Figure 2: Comparison of midterm exam scores by treatment group and gender 


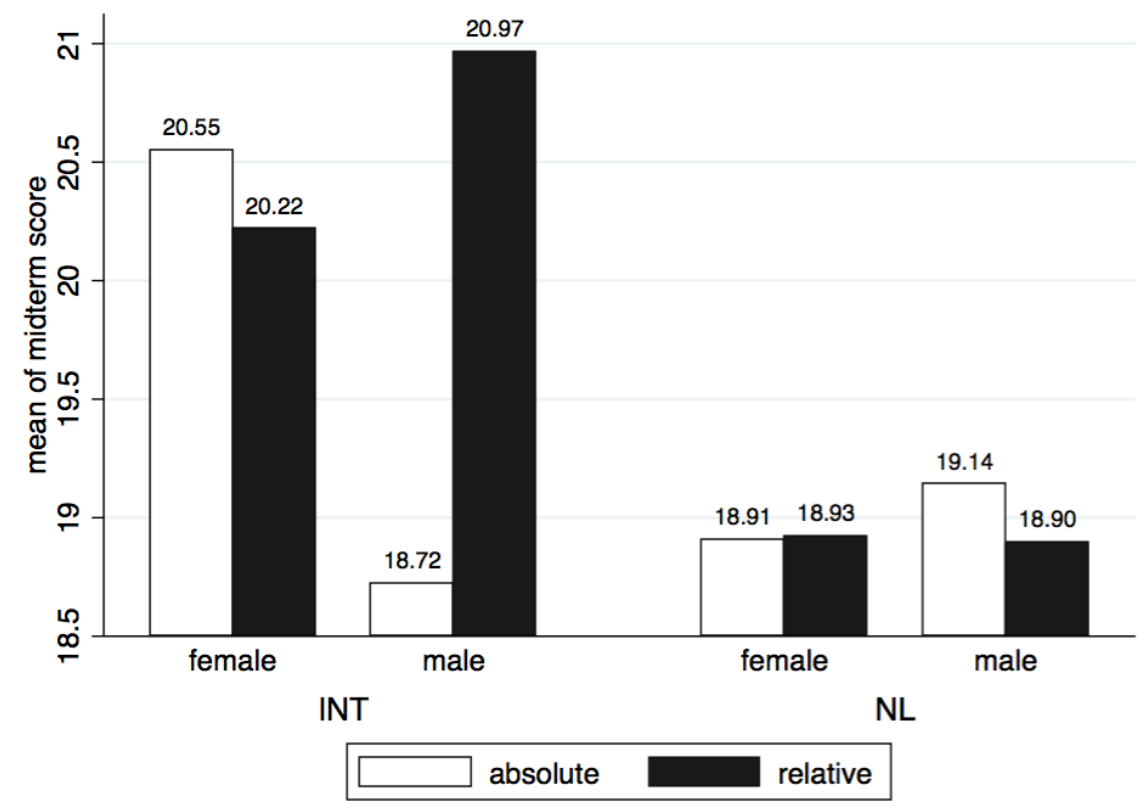

Figure 3: Midterm exam scores by treatment group and gender, separately by study program

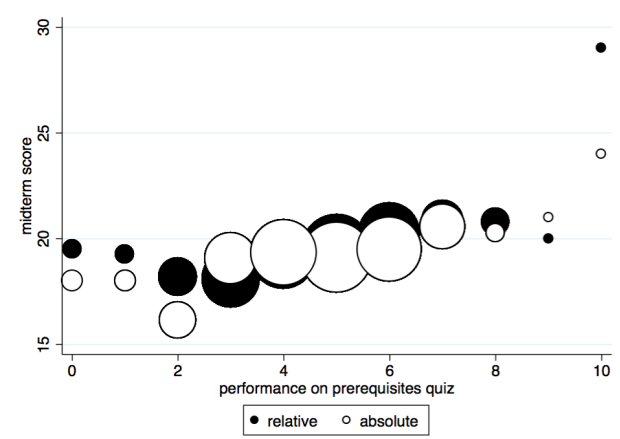

(a) Ability proxy: quiz performance

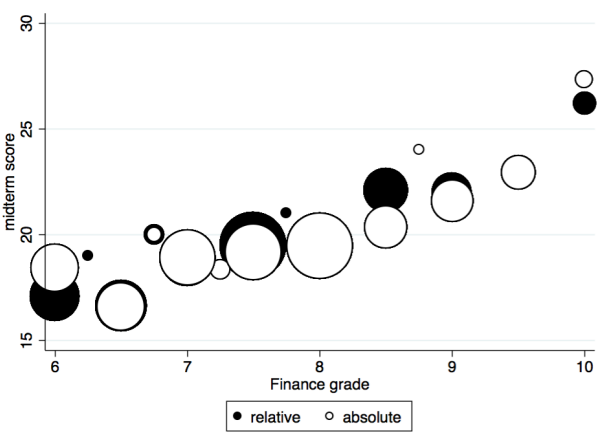

(b) Ability proxy: Finance grade

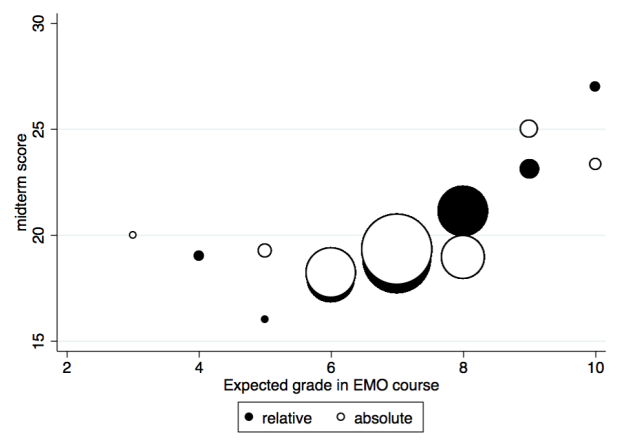

(c) Ability proxy: expected grade

The size of the circles is proportionate to the number of observations in the given category.

Figure 4: Mean midterm score in the two grading groups, by different ability levels 


\section{References}

Azmat, Ghazala, \& Iriberri, Nagore. 2010. The importance of relative performance feedback information: Evidence from a natural experiment using high school students. Journal of Public Economics, 94(7-8), 435-452.

Becker, William E., \& Rosen, Sherwin. 1992. The learning effect of assessment and evaluation in high school. Economics of Education Review, 11(2), 107-118.

Bigoni, Maria, Fort, Margherita, Nardotto, Mattia, \& Reggiani, Tommaso. 2011 (July). Teams or Tournaments? A Field Experiment on Cooperation and Competition among University Students. IZA Discussion Papers 5844. Institute for the Study of Labor (IZA).

Braun, Henry, Kirsh, Irwin, \& Yamamato, Kentaro. 2011. An Experimental Study of the Effects of Monetary Incentives on Performance on the 12th-Grade NAEP Reading Assessment. Teachers College Record, 113(11), 2309-2344.

Budryk, Zack. 2013. Dangerous Curves. Inside Higher Ed, 12 February.

Bull, Clive, Schotter, Andrew, \& Weigelt, Keith. 1987. Tournaments and Piece Rates: An Experimental Study. Journal of Political Economy, 95(1), 1-33.

Croson, Rachel, \& Gneezy, Uri. 2009. Gender Differences in Preferences. Journal of Economic Literature, $\mathbf{4 7}(2), 448-74$.

De Paola, Maria, Gioia, Francesca, \& Scoppa, Vincenzo. 2013 (Dec.). Are Females Scared of Competing with Males? Results from a Field Experiment. IZA Discussion Papers 7799. Institute for the Study of Labor (IZA).

Dohmen, Thomas, Falk, Armin, Huffman, David, Sunde, Uwe, Schüpp, Jurgen, \& Wagner, Gert G. 2011. Individual risk attitudes: measurement, determinants and behavioral consequences. Journal of the European Economic Association, 9(3), 522-550.

Dubey, Pradeep, \& Geanakoplos, John. 2010. Grading exams: 100,99,98,... or A,B,C? Games and Economic Behavior, 69(1), 72-94.

Filippin, Antonio, \& Crosetto, Paolo. 2014 (May). A Reconsideration of Gender Differences in Risk Attitudes. IZA Discussion Papers 8184. Institute for the Study of Labor (IZA).

Fryer, Roland G. 2011. Financial Incentives and Student Achievement: Evidence from Randomized Trials. The Quarterly Journal of Economics, 126(4), 1755-1798.

Gneezy, Uri, \& Pietrasz, Aniela. 2013. When Half of the Men are More Competitive than All Women. Working paper.

Gneezy, Uri, \& Rustichini, Aldo. 2004. Gender and Competition at a Young Age. American Economic Review, 94(2), 377-381. 
Gneezy, Uri, Niederle, Muriel, \& Rustichini, Aldo. 2003. Performance In Competitive Environments: Gender Differences. The Quarterly Journal of Economics, 118(3), 1049-1074.

Green, Jerry R, \& Stokey, Nancy L. 1983. A Comparison of Tournaments and Contracts. Journal of Political Economy, 91(3), 349-64.

Grove, Wayne A., \& Wasserman, Tim. 2006. Incentives and Student Learning: A Natural Experiment with Economics Problem Sets. The American Economic Review, 96(2), pp. 447452.

Guiso, Luigi, Monte, Ferdinando, Sapienza, Paola, \& Zingales, Luigi. 2008. Culture, Gender, and Math. Science, 320(5880), 1164-1165.

Gunther, Christina, Ekinci, Neslihan Arslan, Schwieren, Christiane, \& Strobel, Martin. 2010. Women can't jump?-An experiment on competitive attitudes and stereotype threat. Journal of Economic Behavior \& Organization, 75(3), 395-401.

Harbring, Christine, \& Irlenbusch, Bernd. 2003. An experimental study on tournament design. Labour Economics, 10(4), 443-464.

Harrison, Glenn W., \& List, John A. 2004. Field Experiments. Journal of Economic Literature, 42(4), pp. 1009-1055.

Holmstrom, Bengt. 1982. Moral Hazard in Teams. Bell Journal of Economics, 13(2), 324-340.

Holt, Charles A., \& Laury, Susan K. 2002. Risk Aversion and Incentive Effects. American Economic Review, 92(5), 1644-1655.

Hvide, Hans K. 2002. Pragmatic beliefs and overconfidence. Journal of Economic Behavior E3 Organization, 48(1), 15 - 28. Psychological Aspects of Economic Behavior.

Inspectie van het Onderwijs. 2014. De staat van het onderwijs. Onderwijsverslag 2012/2013. Inspectie van het Onderwijs, April.

Jalava, Nina, Joensen, Juanna Schrøter, \& Pellas, Elin Maria. 2014 (August). Grades and Rank: Impacts of Non-Financial Incentives on Test Performance. Tech. rept. Available at SSRN.

Jaspers, Arnout. 2012. Een voldoende, zonder uitschieters. Wetenschap 24, 12 December.

Jurajda, Stepan, \& Münich, Daniel. 2011. Gender Gap in Performance under Competitive Pressure: Admissions to Czech Universities. American Economic Review, 101(3), 514-18.

Karran, Terrence. 2004. Achieving Bologna convergence: is ECTS failing to make the grade? Higher Education in Europe, 29(3), 411-421.

Landeras, Pedro. 2009. Student effort: standards vs. tournaments. Applied Economics Letters, 16(9), 965-969. 
Lazear, Edward P., \& Rosen, Sherwin. 1981. Rank-Order Tournaments as Optimum Labor Contracts. Journal of Political Economy, 89(5), pp. 841-864.

Leuven, Edwin, Oosterbeek, Hessel, \& van der Klaauw, Bas. 2010. The Effect of Financial Rewards on Students' Achievement: Evidence from a Randomized Experiment. Journal of the European Economic Association, 8(6), 1243-1265.

Levitt, Steven, List, John, Neckermann, Susanne, \& Sadoff, Sally. 2013. The behavioralist goes to school: Leveraging behavioral economics to improve educational performance. Framed Field Experiments 00379. The Field Experiments Website.

Moldovanu, Benny, \& Sela, Aner. 2001. The Optimal Allocation of Prizes in Contests. American Economic Review, 91(3), 542-558.

Morin, Louis-Philippe. forthcoming. Do Men and Women Respond Differently to Competition? Evidence from a Major Education Reform. Journal of Labor Economics.

Müller, Wieland, \& Schotter, Andrew. 2010. Workaholics and Dropouts in Organizations. Journal of the European Economic Association, 8(4), 717-743.

Niederle, Muriel, \& Vesterlund, Lise. 2007. Do Women Shy Away from Competition? Do Men Compete Too Much? The Quarterly Journal of Economics, 122(3), 1067-1101.

Niederle, Muriel, \& Vesterlund, Lise. 2010. Explaining the Gender Gap in Math Test Scores: The Role of Competition. Journal of Economic Perspectives, 24(2), 129-44.

Niederle, Muriel, \& Vesterlund, Lise. 2011. Gender and competition. Annual Review of Economics, 3(September), 601-630.

OECD. 2013. Education at a Glance 2013,. OECD Indicators. OECD Publishing.

Onderstal, Sander. 2014. Economics of Organizations and Markets. Pearson, Amsterdam.

Örs, Evren, Palomino, Frédéric, \& Peyrache, Eloïc. 2013. Performance Gender Gap: Does Competition Matter? Journal of Labor Economics, 31(3), pp. 443-499.

Paredes, Valentina. 2012. Grading System and Student Effort. Mimeo.

Price, Joseph. 2008. Gender Differences in the Response to Competition. Industrial and Labor Relations Review, 61(3), 320-333.

Rosin, Hanna. 2012. The End of Men: And the Rise of Women. Riverhead Books. Penguin Group.

Salvi del Pero, Angelica, \& Bytchkova, Alexandra. 2013. A Bird's Eye View of Gender Differences in Education in OECD Countries. OECD Social, Employment and Migration Working Papers, No. 149. OECD Publishing. 
Sax, Leonard. 2007. Boys Adrift: The Five Factors Driving the Growing Epidemic of Unmotivated Boys and Underachieving Young Men. Basic Books.

Shurchkov, Olga. 2012. Under Pressure: Gender Differences In Output Quality And Quantity Under Competition And Time Constraints. Journal of the European Economic Association, 10(5), 1189-1213.

The Economist. 1999. The trouble with boys. The Economist, May 27.

van Dijk, Frans, Sonnemans, Joep, \& van Winden, Frans. 2001. Incentive systems in a real effort experiment. European Economic Review, 45(2), 187 - 214. 


\section{Appendix A: Sections from the Course Manual}

\section{Grading the exams}

The lecturers of the University of Amsterdam are constantly striving to improve their teaching and evaluation practices. As part of this initiative, during the EMO course we will test two different grading schemes that are recognized by the university: all students will experience both an absolute and a relative grading scheme. These grading schemes determine how exam scores are translated into grades.

\section{Absolute grading}

Under an absolute scheme, students' grades depend solely on their individual absolute performance in the exams. Specifically, the exam grade is calculated as follows:

$$
\text { Grade exam }=10-0.4^{*}(\text { number of errors })
$$

We round the grade to the nearest integer and we do not assign a grade below 2. This implies that exam scores translate into exam grades according to the table below:

\begin{tabular}{cc}
\hline \hline $\begin{array}{c}\text { Exam score } \\
\text { (=points earned) }\end{array}$ & Grade \\
\hline $29-30$ & 10 \\
$27-28$ & 9 \\
$24-26$ & 8 \\
$22-23$ & 7 \\
$19-21$ & 6 \\
$17-18$ & 5 \\
$14-16$ & 4 \\
$12-13$ & 3 \\
$0-11$ & 2 \\
\hline
\end{tabular}

\section{Relative grading}

Under a relative grading scheme, or grading on a curve, students' grades depend on how well they perform in the exams compared to other students taking this course. It is not the individual score, but the students' position in the class score distribution (i.e., the students' rank among all students taking the exam) that determines the exam grade. For this course the curve is fixed so that the average score translates into an exam grade of 6 , and the highest performing $1 \%$ of students receive a grade 10 while the lowest performing $1 \%$ get a grade 2 . We illustrate this scheme by the figure and the table below: 


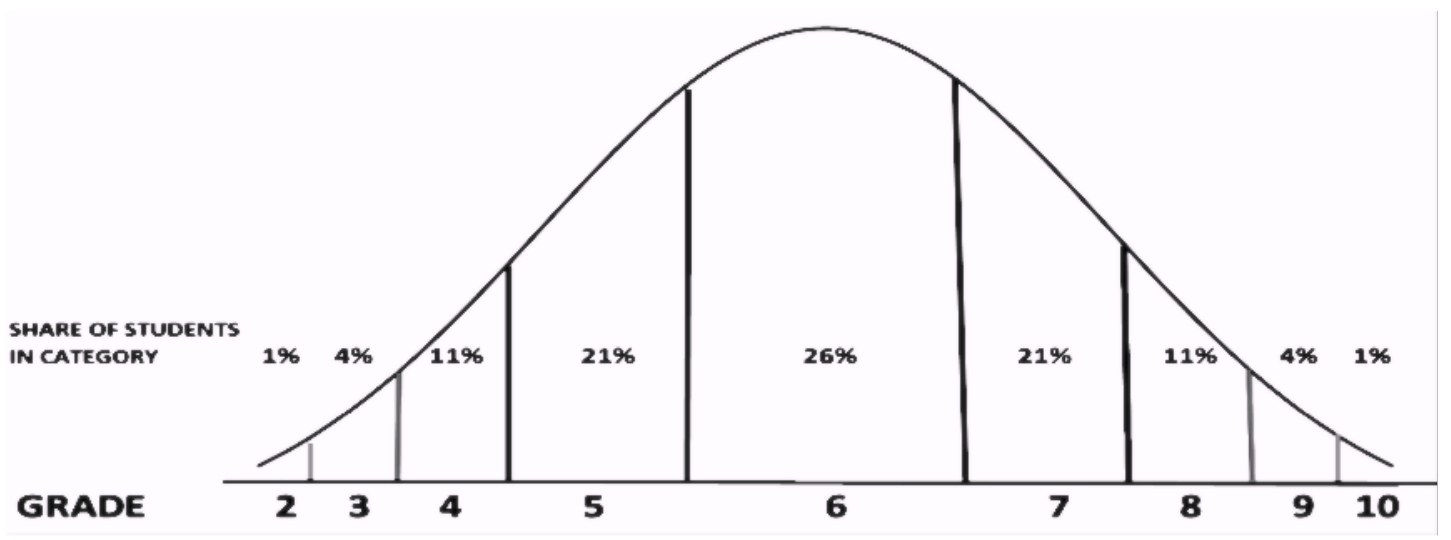

\begin{tabular}{cc}
\hline \hline $\begin{array}{c}\text { Relative rank } \\
\text { (calculated from the top) }\end{array}$ & Grade \\
\hline $1 \%$ & 10 \\
$2-5 \%$ & 9 \\
$6-16 \%$ & 8 \\
$17-37 \%$ & 7 \\
$38-63 \%$ & 6 \\
$64-84 \%$ & 5 \\
$85-95 \%$ & 4 \\
$95-99 \%$ & 3 \\
$99-100 \%$ & 2 \\
\hline
\end{tabular}

\section{Comparison of the schemes}

In order to compare the two grading schemes, we will randomly divide all students into two grading groups: the blue group and the yellow group. Students in the two groups will take exams of the same difficulty level but will face different grading schemes:

BLUE group: midterm exam graded under absolute, final exam graded under relative scheme

YELLOW group: midterm exam graded under relative, final exam graded under absolute scheme

This way fairness is ensured: all students will experience both grading schemes, only the timing is different (remember: the midterm and final exams have equal weights and cover the same amount of study material). The grades of students under the relative schemes are always determined compared to other exam takers in their grading group, not the whole class.

Before the start of the course, we will notify you of your grading group via e-mail and a Blackboard message. Please make sure you know which grading group you belong to, as it is important not only for your exam but also for the composition of homework groups. 


\section{Appendix B: Screenshots from the survey}

Figure 5: Example of a multiple-choice quiz question

\section{FACULTY OF ECONOMICS AND BUSINESS}

Question 2.

What is the derivative of the function $f(x)=(x-5) / 2 x$ ?

$f^{\prime}(x)=5 \log (x) / 2$

$f^{\prime}(x)=0.5 x$

$f(x)=2.5 / x^{2}$

$f^{\prime}(x)=(2 x-5) / 4 x^{2}$

Figure 6: Eliciting risk preferences

\section{Your payment}

One of the 10 decisions will be randomly selected for payment, and the outcome (high or low payoff) will be determined according to the probabilities stated in that decision. The payoff from this decision will be calculated according to the gamble you selected and will be added to your survey account.

\begin{tabular}{|c|c|c|c|c|}
\hline & \multicolumn{2}{|c|}{ Option $\mathbf{A}^{*}$} & \multicolumn{2}{|c|}{ Option $\mathrm{B}^{*}$} \\
\hline & $€ 40$ & $€ 32$ & $€ 77$ & $€ 2$ \\
\hline Decision 1 & $10 \%$ & $90 \%$ & $10 \%$ & $90 \%$ \\
\hline Decision 2 & $20 \%$ & $80 \%$ & $20 \%$ & $80 \%$ \\
\hline Decision 3 & $30 \%$ & $70 \%$ & $30 \%$ & $70 \%$ \\
\hline Decision 4 & $40 \%$ & $60 \%$ & $40 \%$ & $60 \%$ \\
\hline Decision 5 & $50 \%$ & $50 \%$ & $50 \%$ & $50 \%$ \\
\hline Decision 6 & $60 \%$ & $40 \%$ & $60 \%$ & $40 \%$ \\
\hline Decision 7 & $70 \%$ & $30 \%$ & $70 \%$ & $30 \%$ \\
\hline Decision 8 & $80 \%$ & $20 \%$ & $80 \%$ & $20 \%$ \\
\hline naninin-n & ( & $10 \%$ & $90 \%$ & $10 \%$ \\
\hline \multirow{2}{*}{\multicolumn{2}{|c|}{$\begin{array}{l}\text { I always prefer Option B } \\
\text { From Decision } 2 \text { onwards I prefer Option B } \\
\text { From Decision } 3 \text { onwards I prefer Option B } \\
\text { From Decision } 4 \text { onwards I prefer Option B } \\
\text { From Decision } 5 \text { onwards I prefer Option B } \\
\text { From Decision } 6 \text { onwards I prefer Option B } \\
\text { From Decision } 7 \text { onwards I prefer Option B } \\
\text { L From Decision } 8 \text { onwards I prefer Option B } \\
\text { From Decision } 9 \text { onwards I prefer Option B } \\
\text { b In Decision } 10 \text { I start to prefer Option B } \\
\text { I always prefer Option A }\end{array}$}} & $0 \%$ & $100 \%$ & $0 \%$ \\
\hline & & \multicolumn{3}{|c|}{$\begin{array}{l}\text { bility of receiving } € 40 \text { and } 90 \% \text { probability of receiving } € 32 \text {. } \\
\text { h decision did you first start to prefer Option B? This implies that } \\
\text { and from this decision onwards, you prefer Option B. }\end{array}$} \\
\hline & & & & \\
\hline
\end{tabular}




\section{Appendix C: Additional tables and figures}

Table C1: Comparison of means between treatment groups, by gender

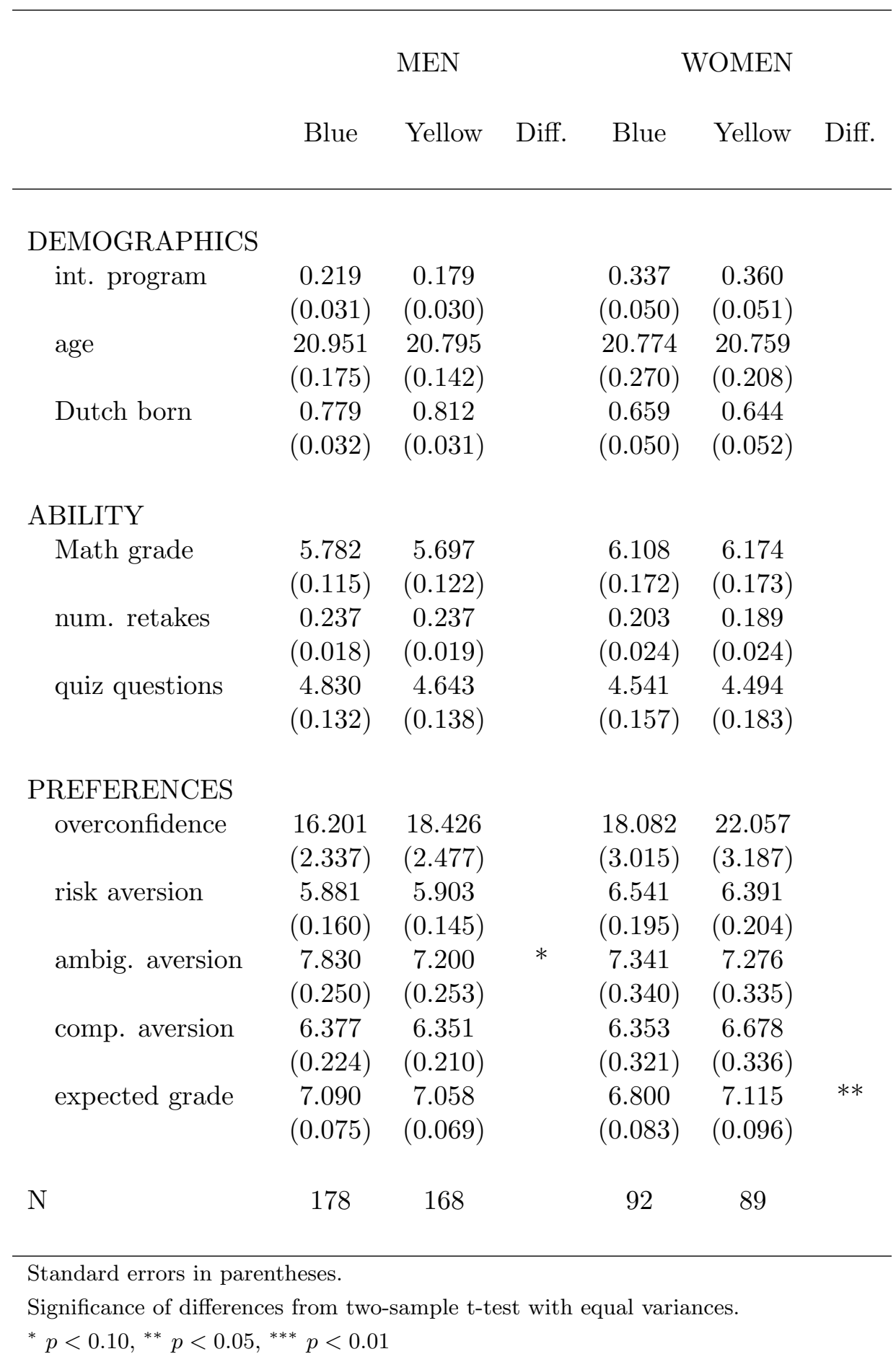


Table C2: Estimates of the effect of relative grading on midterm scores, including interaction terms
(1)
$(2)$
$(3)$
$(4)$
$(5)$

\begin{tabular}{lccccc}
\hline & & & & & \\
relative & -0.010 & 0.614 & -0.046 & $-1.701^{* *}$ & -0.500 \\
& $(0.722)$ & $(1.441)$ & $(1.079)$ & $(0.816)$ & $(0.498)$ \\
relative*male & $1.344^{* *}$ & $1.158^{*}$ & $1.167^{*}$ & $1.269^{* *}$ & $1.199^{* *}$ \\
& $(0.590)$ & $(0.606)$ & $(0.601)$ & $(0.609)$ & $(0.593)$ \\
male & $-0.908^{* *}$ & $-0.833^{*}$ & $-0.826^{*}$ & $-0.869^{*}$ & $-0.858^{*}$ \\
& $(0.455)$ & $(0.450)$ & $(0.450)$ & $(0.454)$ & $(0.450)$ \\
relative*Dutch & -0.894 & & & & \\
& $(0.674)$ & & & & \\
relative*Math & & -0.203 & & & \\
& & $(0.210)$ & & & \\
relative*risk & & & -0.092 & & \\
& & & $(0.150)$ & & \\
relative*comp. & & & & 0.158 & \\
& & & & $(0.100)$ & \\
relative*overconf. & & & & & -0.007 \\
& & $\checkmark$ & $\checkmark$ & $\checkmark$ & $(0.008)$ \\
Demographic controls & $\checkmark$ & $\checkmark$ & $\checkmark$ & $\checkmark$ & $\checkmark$ \\
Ability controls & $\checkmark$ & $\checkmark$ & $\checkmark$ & $\checkmark$ & $\checkmark$ \\
Preference controls & $\checkmark$ & $\checkmark$ & $\checkmark$ & 419 & 419 \\
$N$ & 419 & 419 & 419 & 419 \\
$R^{2}$ & 0.277 & 0.276 & 0.275 & 0.278 & 0.275 \\
& & & & & \\
& & & & &
\end{tabular}

Results from OLS regressions; dependent variable: midterm score.

Standard errors, clustered on the homework team level, in parentheses.

${ }^{*} p<0.10,{ }^{* *} p<0.05,{ }^{* * *} p<0.01$ 
Table C3: Comparison of means by gender and study program

MEN

Dutch International Diff. Dutch International Diff.

\begin{tabular}{lcccccc}
\hline & & & & & & \\
lecture attendance & 1.191 & 1.262 & & 1.265 & 1.131 & \\
& $(0.058)$ & $(0.127)$ & & $(0.081)$ & $(0.120)$ & \\
tutorial attendance & 1.473 & 1.493 & & 1.458 & 1.270 & \\
& $(0.062)$ & $(0.114)$ & & $(0.093)$ & $(0.116)$ & $* * *$ \\
handing in HW & 0.729 & 0.942 & $* * *$ & 0.831 & 0.968 & $* * *$ \\
& $(0.027)$ & $(0.028)$ & & $(0.035)$ & $(0.022)$ & \\
average HW grade & 6.841 & 7.127 & $* *$ & 7.063 & 6.952 & \\
& $(0.084)$ & $(0.088)$ & & $(0.137)$ & $(0.100)$ & $* * *$ \\
study time & 2.267 & 2.495 & $* *$ & 2.430 & 2.948 & $* * 2$ \\
& $(0.054)$ & $(0.095)$ & & $(0.085)$ & $(0.098)$ &
\end{tabular}

Standard errors in parentheses.

Significance of difference from two-sample t-test with unequal variances.

${ }^{*} p<0.10,{ }^{* *} p<0.05,{ }^{* * *} p<0.01$

Table C4: Estimates of the effect of relative grading on midterm scores: international program, by gender

MEN

WOMEN

No controls With controls No controls With controls

relative

$2.243^{* *}$

$1.497^{*}$

$-0.333$

$-0.823$

(1.005)

(0.769)

(1.075)

(0.725)

Demographic controls

Ability controls

Preference controls
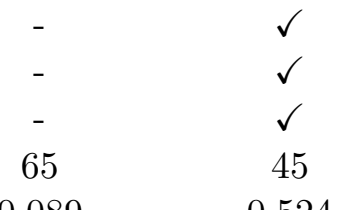

$N$

0.089

45

61

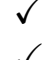

$-$

$-$

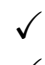

45

$R^{2}$

0.524

0.002

0.573

Results from OLS regressions; dependent variable: midterm score.

Standard errors, clustered on the homework team level, in parentheses.

${ }^{*} p<0.10,{ }^{* *} p<0.05,{ }^{* * *} p<0.01$ 
Table C5: Estimates of the effect of relative grading on preparation behavior: international program

\begin{tabular}{lcccc}
\hline & & & & $(3)$ \\
& $(1)$ & $(2)$ & $(4)$ \\
& handing in HW & avg. HW & attendance & study time \\
& & & & \\
\hline & & & & \\
relative & $(267.039$ & $0.756^{* *}$ & 0.144 & 0.136 \\
& -3.631 & $(0.278)$ & $(0.358)$ & $(0.205)$ \\
relative*male & $(267.404)$ & -0.460 & 0.055 & 0.217 \\
& -0.092 & $0.635^{* *}$ & -0.038 & $-0.402^{* *}$ \\
male & $(0.458)$ & $(0.284)$ & $(0.378)$ & $(0.180)$ \\
& limited & $\checkmark$ & $\checkmark$ & $\checkmark$ \\
Demographic controls & - & $\checkmark$ & $\checkmark$ & $\checkmark$ \\
Ability controls & - & $\checkmark$ & $\checkmark$ & $\checkmark$ \\
Preference controls & 132 & 90 & 90 & 74 \\
$N$ & & 0.442 & 0.119 & 0.283 \\
$R^{2}$ & & & & \\
& & & & \\
\hline
\end{tabular}

(1): probit, (2)-(4): OLS regressions; dependent variables indicated in column headers. Standard errors, clustered on the homework team level, in parentheses.

${ }^{*} p<0.10,{ }^{* *} p<0.05,{ }^{* * *} p<0.01$

Table C6: Share of women among best and worst performers, by grading scheme

\begin{tabular}{lccc}
\hline & & & \\
& & & \\
& & & \\
& & & \\
Worst quartile & 0.267 & 0.345 & 0.059 \\
& $(0.058)$ & $(0.063)$ & $(0.078)$ \\
Best quartile & 0.392 & 0.333 & -0.078 \\
& $(0.057)$ & $(0.053)$ & $(0.085)$ \\
& \multicolumn{3}{l}{} \\
\hline Standard errors in parentheses; ${ }^{*} p<0.10,{ }^{* *} p<0.05,{ }^{* * *} p<0.01$ \\
Significance of difference from two-sample t-test with unequal variances.
\end{tabular}




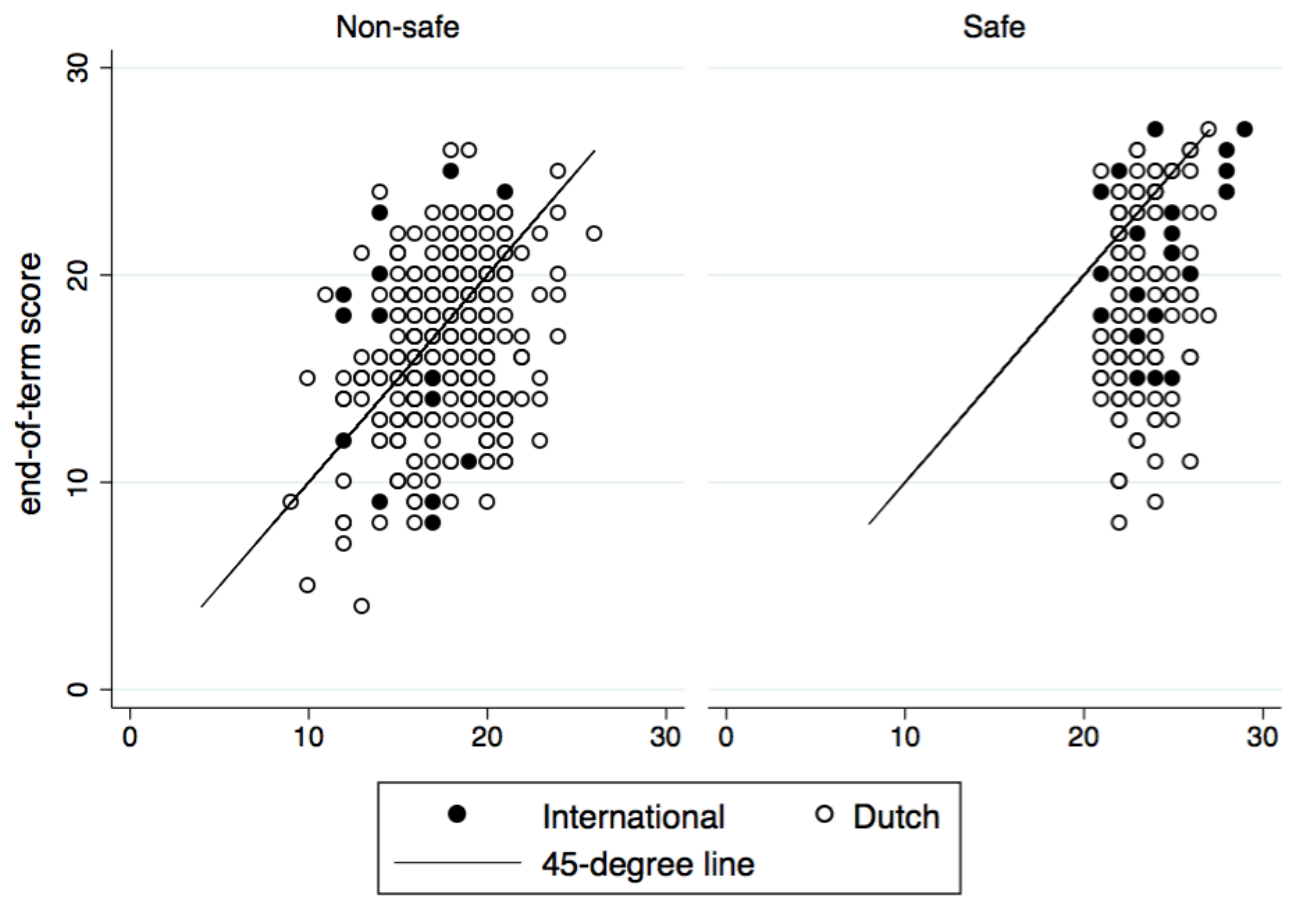

Figure C1: End-term scores plotted against midterm scores, separately for "non-safe" and "safe" students

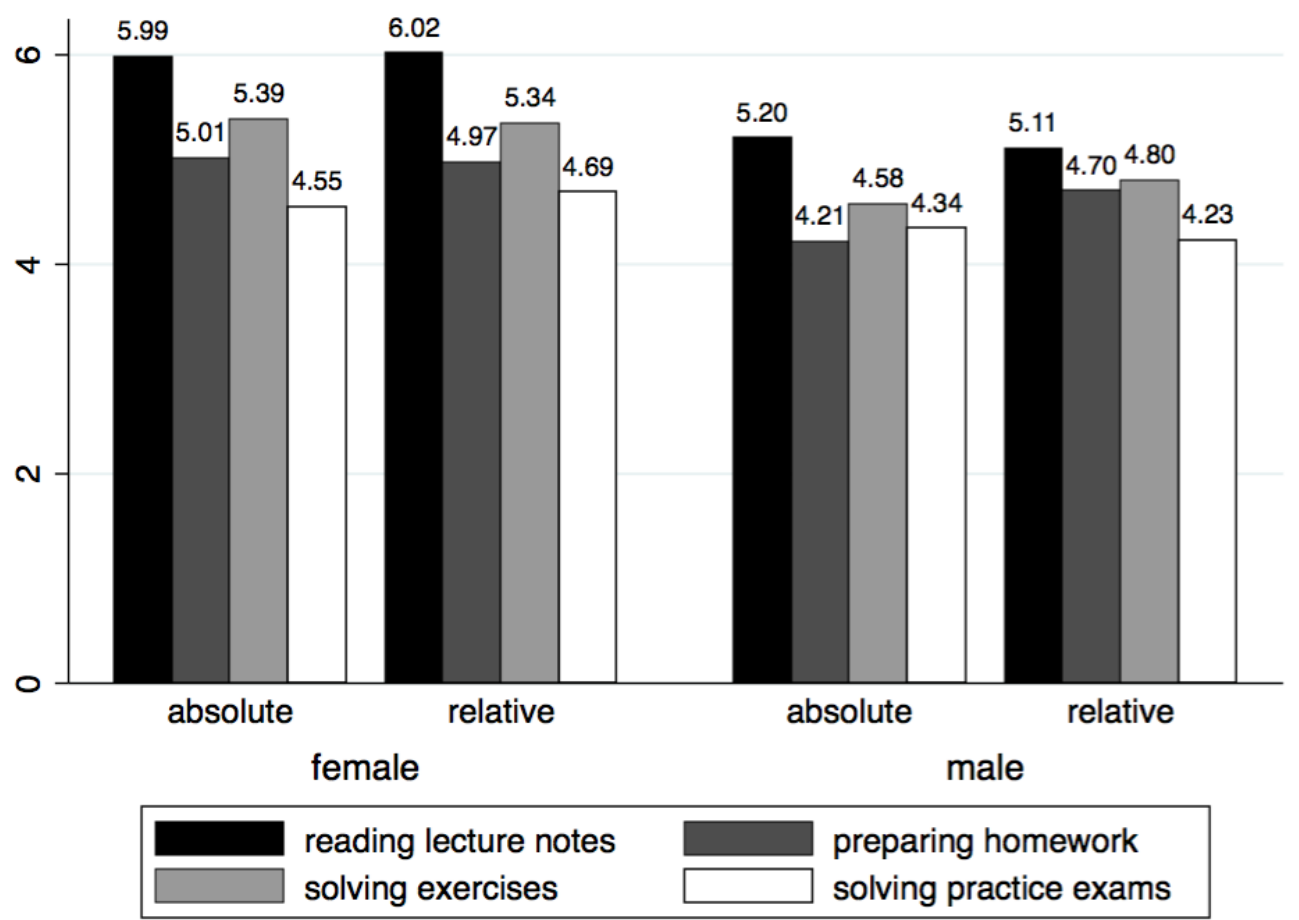

Figure C2: Self-reported study times on different activities by treatment group and gender 